Revista lus et Praxis, Año 20, No 1, 2014, pp. 279 - 318

ISSN 0717 - 2877

Universidad de Talca - Facultad de Ciencias Jurídicas y Sociales

"El Derecho de familia en Chile. Evolución y nuevos desafíos"

María José Arancibia Obrador - Pablo Cornejo Aguilera

Colaboración recibida el 25 de septiembre y aprobada el 13 de noviembre de 2013

\title{
El Derecho de familia en Chile. Evolución y nuevos desafíos
}

\author{
María José Arancibia Obrador* \\ Pablo Cornejo Aguilera**
}

\section{Las transformaciones del Derecho de familia, un proceso todavía en desarrollo}

El Derecho de familia es la rama del Derecho civil que más transformaciones ha experimentado desde la promulgación del Código civil el año 1855, hecho que no debe resultarnos extraño, si consideramos los profundos cambios habidos en su objeto de regulación, la familia. En efecto, el modelo considerado digno de protección por el codificador de 1855, en el contexto de una sociedad tradicional, preferentemente agraria y religiosa como la chilena, supuso la consagración de un ideal de familia que se había venido construyendo en el mundo occidental desde la edad media, donde ésta se encontraba fundada en la existencia de un matrimonio, celebrado según el rito religioso católico y cuya regulación quedaba entregada íntegramente al Derecho canónico, dada su naturaleza sacramental, el cual además de tener un carácter indisoluble, confería grandes poderes al marido, cabeza de la familia, tanto sobre la persona y los bienes de su mujer ${ }^{1}$, como sobre la persona y los bienes de sus hijos², siendo

\footnotetext{
* Profesora Invitada Universidad de Talca y Universidad Gabriela Mistral. Candidata a Magíster de Derecho, mención Derecho Privado (Universidad de Chile). LL.M en Economía y Finanzas (Universidad Gabriela Mistral). Correo electrónico: marancibia@utalca.cl.

** Académico del Departamento de Derecho Privado de la Facultad de Derecho de la Universidad de Chile. Becario gobierno suizo para estudios de postgrado. Actualmente cursando Master, Droit international et comparé (Universidad de Lausanne). Correo electrónico: pabloandres.cornejoaguilera@unil.ch.

1 Expresado en el deber de obediencia respecto de su marido que la antigua legislación imponía sobre la mujer, piedra de base de la potestad marital; y en el hecho que el único régimen de bienes disponible para los cónyuges, la sociedad conyugal, importara una suerte de capitis diminutio para la mujer, quien a partir del matrimonio devenía incapaz relativa y debía confiar la administración de todos los bienes a su marido.

2 En el modelo consagrado en el Código civil originario, es posible advertir la existencia de una verdadera autoridad paterna sobre el hijo, reflejado en su derecho a corregirlo, que llevado a su extremo permitía al padre obtener su internamiento en un recinto correccional, por un periodo limitado de
} 
una de sus misiones el asegurar un espacio de certeza para la procreación ${ }^{3}$ y la transmisión de la propiedad a través de la herencia ${ }^{4-5}$.

En este contexto, debe destacarse el hecho que la primera gran transformación en la regulación de la familia fuera de orden eminentemente político y estuviera fuertemente influenciada por las doctrinas laicistas, desarrolladas a partir de la Ilustración ${ }^{6}$ y reflejadas particularmente en la legislación francesa ${ }^{7}$ : acorde con ello, a partir del año 1884 el legislador chileno afirmaría la competencia de las autoridades civiles para dictar la normativa concerniente al matrimonio y conocer de las causas que con su ocasión se susciten, privando a las autoridades eclesiásticas de una potestad que venían ejerciendo casi sin contrapesos desde la edad media ${ }^{8}$. De esta manera, dentro de las Ilamadas "Ie-

tiempo. En el ámbito patrimonial, el padre (y sólo el padre) gozaba de la administración de los bienes del hijo no emancipado, a través de la figura de la patria potestad.

3 Respaldada por el reconocimiento de la antigua máxima romana "pater is est quem nuptiae demonstrant", recogida en el actual artículo 18 del Código civil (en adelante CC).

4 Todas estas características, Ilevaron a que don Pedro LIRA URQUIETA en su clásica obra sobre el Código civil identificara dentro de los principios jurídicos que informan la obra codificadora el de la "constitución cristiana de la familia y su protección", lo que se expresa particularmente en el hecho el legislador no habría dudado en admitir el matrimonio monógamo e indisoluble como la base única de la familia y por ende, como el fundamento de la sociedad. LIRA URQUIETA, Pedro (1956): El Código Civil Chileno y su Época (Santiago, Editorial Jurídica de Chile), pp. 63-67.

5 En este mismo sentido se expresa el profesor DeL PICó, al decir que "La familia a que estos Códigos se refieren es la que corresponde a una sociedad predominantemente agrícola, como era la que existía en Chile a mediados de ese siglo. Esa familia era patriarcal o paternal, vale decir, el padre constituía el personaje principal del grupo, debía protección a la mujer y a los hijos y era el administrador de la fortuna familiar. Podía obligar a su mujer a vivir con él y a seguirlo adondequiera que trasladara su residencia (antigua redacción del artículo 133 del Código Civil). Un autor señaló que el destino de la mujer durante la vigencia del primitivo Código Civil era pasar del yugo del padre al yugo del marido. El matrimonio se celebraba conforme a las normas de la Iglesia Católica y era indisoluble: el que se casaba una vez, se casaba para siempre". Dę PICó RuBıo, Jorge (2011): "Principios Fundamentales del Sistema Matrimonial Chileno", en:VV.AA., Estudios de Derecho Civil (Santiago, Editorial Abeledo-Perrot), tomo V, pp. 135-136.

6 Colnc, Helmut (1996): Derecho Privado Europeo. El Siglo XIX (traducc. Antonio Pérez San Martín (Madrid, Fundación Cultural del Notariado), tomo II, pp. 379-381.

7 En Francia, sin considerar la problemática de los matrimonios celebrados entre protestantes, el reconocimiento del carácter secular del matrimonio se produjo por primera vez durante la época revolucionaria, declarando solemnemente el artículo 7 de la Constitución de 1791 que "La loi ne considère le mariage que comme contrat civil...". Posteriormente, esta afirmación general sería concretizada en el decreto legislativo de 20 de septiembre de 1792, y reiterada en el Code civil de 1804. El carácter civil del matrimonio no se vería afectado por la restauración borbónica, a diferencia de lo que ocurriría con el divorcio. Basdevant-Gaudemet, Brigitte; Gaudemet, Jean (2000): Introduction Historique au Droit. XIIle-XXe Siècles (Paris, L.G.D.J.), pp. 352-354.

8 En este sentido señala Htun que "Luego de la asunción al poder de las élites liberales iuspositivistas entre mediados y fines del siglo diecinueve, se redefinieron las relaciones entre Iglesia y Estado. En Chile, la Ley de Matrimonio Civil de 1884 hizo obligatoria la ceremonia civil para los cónyuges. En la misma época, se promulgó la ley de cementerios laicos, que privó a la lglesia del control sobre los 
yes laicas" se aprobaría la primera ley de matrimonio civil en Chile, regulación que se caracterizaría dos importantes elementos: mientras, por una parte, su aprobación implicaba una ruptura con la tradición, reflejada en el hecho que en el futuro solamente sería protegida la pareja que contrajese matrimonio ante el oficial del registro civil $^{9}$; por otra, la ley estaría construida sobre las mismas bases que la regulación canónica, sin afectar de manera alguna el contenido de esta institución ${ }^{10}$, hecho que queda gráficamente expresado en el carácter indisoluble que tendría el vínculo matrimonial hasta el año $2004^{11}$.

cementerios (poniéndolos a disposición de todos los credos), y la Ley del Registro Civil, que retiró de las manos de los párrocos los registros de nacimientos, casamientos y muertes. La Ley de Matrimonio Civil fue un acto radical, que privó a la Iglesia de su papel tradicional en la regulación legal de la familia. Como señala Mecham, el clero 'protestó, amenazó e incluso llegó al extremo de intentar impedir el matrimonio de cualquiera que hubiere votado a favor de la medida. Fue tal la oposición que fomentó el clero en contra de esa 'ley sacrílega', que el país parecía estar al borde de una revolución". Htun, Mala (2010): Sexo y Estado. Aborto, Divorcio y Familia bajo Dictaduras y Democracias en América Latina (Santiago, Ediciones Universidad Diego Portales), pp. 83-84.

9 Esta situación se mantendría hasta la promulgación de la Ley № 19.947 (nueva ley de matrimonio civil) en 2004, cuyo artículo 20 autoriza la celebración del matrimonio ante un ministro de culto, sujetando la validez del matrimonio a su posterior ratificación ante el oficial civil. Sin embargo, los resultados de esta modificación legal están lejos de crear un sistema alternativo de celebración del matrimonio, como el actualmente vigente en España. Para conocer la discusión sobre el punto, consúltese CoRRAL TALCIANI, Hernán (2010): "El Matrimonio Religioso con Efectos en Chile: Un Desarrollo -Todavía Parcial- de la Ley de Cultos", en: Jorge del Picó Rubio (Coordinador), Derecho de la Libertad de Creencias (Santiago, Abeledo-Perrot), pp. 157-162; Salinas Araneda, Carlos (2010): "El Reconocimiento del Matrimonio Religioso en el Derecho Positivo del Estado de Chile: Un Viejo Tema Aún Pendiente", en: Revista de Derecho. Universidad Austral, Valdivia (Vol. XXIII, № 1), pp. 58-78.

${ }^{10}$ Como gráficamente señala el profesor SALINAS "El matrimonio civil, sin embargo, no quedó encerrado en los Estados que habían recibido las nuevas ideas religiosas, sino que llegó también a los países de cultura católica. Cuando ello ocurrió y nuestros legisladores se vieron en la necesidad de regular esta nueva figura, no tuvieron que 'inventar' nada porque todo ya estaba 'inventado', de manera que no tuvieron más que limitarse a hacer una lectura en clave laica del matrimonio canónico, eliminando todo lo que tuviera carácter religioso, pero conservando las estructuras técnicas. Y esto, no sólo respecto a los elementos menos importantes del matrimonio, sino que, incluso, como en el caso de Chile, conservando en el matrimonio civil una cualidad tan esencial del matrimonio canónico como la indisolubilidad". Salinas Araneda, Carlos (2010): "El Reconocimiento del Matrimonio Religioso en el Derecho Positivo del Estado de Chile: Un Viejo Tema Aún Pendiente", en: Revista de Derecho. Universidad Austral, Valdivia (Vol. XXIII, № 1). En el mismo sentido, Corral TalCIANI, Hernán (2011): Separación, Nulidad y Divorcio. Análisis desde los Principios y las Reglas de la Ley de Matrimonio Civil (Santiago, Abeledo-Perrot), pp. 24-25. Para una sucinta revisión del panorama europeo, consúltese Colng, Helmut (1996): Derecho Privado Europeo. El Siglo XIX (traducc. Antonio Pérez San Martín (Madrid, Fundación Cultural del Notariado), tomo II, pp. 383-389.

${ }^{11}$ Con todo, desde el año 1925 en Chile se desarrolló una marcada tendencia jurisprudencial que conferiría a aquellas parejas cuyo proyecto de vida en común hubiese fracasado de una salida distinta, la nulidad. Sin embargo, como señala el profesor TAPIA "la nulidad fraudulenta significaba también un trámite engorroso y relativamente costoso, y según el Censo del año 2002, del total de parejas que se declararon separadas (más de medio millón de personas) sólo un 10\% se encontraban anuladas. Por lo demás, la nulidad quedaba también entregada al azar de la integración de la sala del tribunal cole- 
Durante todo el transcurso del siglo XX seguirían suscitándose reformas en el Derecho de familia ${ }^{12}$. La primera de ellas, introducida por medio de la Ley № 5.521 de 19 de diciembre de 1934, tuvo como finalidad mejorar la posición de la mujer casada, bastante desmedrada en el Código ${ }^{13}$. Así, se le reconoció el derecho a ejercer la patria potestad en forma subsidiaria al padre; se le confirió plena capacidad jurídica en aquellos casos en que se encuentre divorciada perpetuamente ${ }^{14}$ o separada totalmente de bienes; reconociendo la progresiva incorporación de la mujer al mundo laboral, se creó un patrimonio especial para aquellos casos en que, encontrándose autorizada por su marido ${ }^{15}$, ejerciera una actividad profesional (los denominados bienes reservados de la mujer casada en régimen de sociedad conyugal); y se permitió a los esposos pactar el régimen de separación total de bienes en las capitulaciones matrimoniales, reforma que implicaba un profundo avance frente a la situación vigente hasta la fecha, en que la sociedad conyugal aparecía como un régimen necesario ${ }^{16}$. Con posterioridad,

giado que pronunciará sobre ella, puesto que algunos ministros eran reticentes a concederlas. En ese sentido, la nueva Ley de Matrimonio Civil no introdujo en verdad el divorcio vincular en Chile, sino que lo democratizó". TAPIA Rodríguez, Mauricio (2008): "Del Derecho de Familia Hacia un Derecho de las Familias", en: Alejandro Guzmán Brito (Editor), Estudios de Derecho Civil III. Jornadas Nacionales de Derecho Civil. Valparaíso, 2007 (Santiago, Abeledo-Perrot), pp. 162-163.

12 Para una revisión completa de la evolución del Derecho de familia chileno, TAPIA Rodrícuez, Mauricio (2005): Código Civil de Chile. Evolución y Perspectivas (Santiago, Editorial Jurídica de Chile), pp. 102 y ss.; Corral Talcianı, Hernán (2005): "La Familia en los 150 Años del Código Civil Chileno", en: Revista Chilena de Derecho. Pontificia Universidad Católica de Chile (Vol. 32, № 3), pp. 429-438.

${ }^{13}$ En este sentido, la legislación chilena no difiere de otras codificaciones liberales decimonónicas, que consideran al marido la cabeza de la familia, que tiene un deber de proteger a la mujer, tanto en sus asuntos personales como en los patrimoniales, siendo una figura a quien la mujer debe obediencia, manteniéndose en esencia la concepción patriarcal del matrimonio que venía desde el más antiguo Derecho común. Véase sobre este punto, ColNG, Helmut (1996): Derecho Privado Europeo. El Siglo XIX (traducc. Antonio Pérez San Martín (Madrid, Fundación Cultural del Notariado), tomo II, p. 388.

${ }^{14}$ Entendido este "divorcio perpetuo" en el contexto de una normativa que no reconocía el divorcio vincular simplemente como una suerte de separación judicial, que provocaba el cese del deber que tienen los cónyuges de vivir juntos.

${ }_{15}$ Para un análisis más detallado, Hun, Mala (2010): Sexo y Estado. Aborto, Divorcio y Familia bajo Dictaduras y Democracias en América Latina (Santiago, Ediciones Universidad Diego Portales), p. 94.

${ }^{16}$ Como señala la profesora SCHMIDT, al momento de la dictación del Código este régimen sólo podía coexistir con una separación parcial de bienes convenida en las capitulaciones matrimoniales otorgadas con anterioridad al matrimonio. Con todo, el reconocimiento de una mayor autonomía en el ámbito del régimen de bienes deberá esperar sucesivas reformas, comenzando con la Ley № 7.612 de 21 de octubre de 1943, que permitiría pactar la separación total de bienes durante el matrimonio; siguiendo con la Ley № 10.271 de 2 de abril de 1952, que simplificaría la adopción del régimen al permitir que éste sea pactado por medio de una declaración conjunta que efectúen los esposos al momento de contraer matrimonio; para finalizar con la Ley $\mathrm{N}^{\circ}$ 19.335, de 23 de septiembre de 1994, que incorporaría un nuevo régimen de bienes convencional y alternativo, la participación en los gananciales. SснміDт Hотт, Claudia (1999): "Régimen Patrimonial y Autonomía de la Voluntad", en: Revista Chilena de Derecho. 
nuevas reformas serían introducidas a través de las Leyes $\mathrm{N}^{\circ} \mathrm{s} .7612$ y 7613, ambas de 21 de octubre de 1943, y de la Ley No 10.271 de 2 de abril de 1952, que mejoraría en algo la posición del hijo nacido fuera del matrimonio que hubiera sido reconocido por su padre, sin llegar a equipararlo con el hijo legítimo.

Sin embargo, sería en forma coincidente con el pleno restablecimiento de la institucionalidad democrática que el proceso de modernización del Derecho de familia chileno tomaría un nuevo y definitivo impulso: desde la igualación de los cónyuges y el fin de la incapacidad relativa que afectaba a la mujer casada en sociedad conyugal ${ }^{17}$, ocurrida con la Ley $N^{\circ} 18.802$ de 1989, el antiguo edificio construido por don Andrés Bello ha ido dando lugar a una nueva forma de concebir las relaciones familiares, que pone énfasis en una visión asociativa de ésta, estructurada en torno a las ideas de igualdad y solidaridad entre sus miembros, quienes se deben mutuo respeto y protección; lo cual se vería complementado con el reconocimiento del interés superior de los niños como principio que debe informar toda decisión que concierna a éstos, como consecuencia de la entrada en vigencia en el país de la Convención de los Derechos del Niño.

De esta forma, como consecuencia del proceso que en este momento se inicia, podemos observar que la familia ha pasado de ser considerada por la legislación chilena como una institución fundada exclusivamente en la existencia del vínculo matrimonial, destinada a crear un marco único e indisoluble que permita la procreación y crianza de los hijos ${ }^{18}$, a constituir un espacio definido por la existencia de vínculos de afectividad y solidaridad entre sus miembros ${ }^{19}$,

Pontificia Universidad Católica de Chile (Vol. 26, №1), pp. 107-109; Corral TALCIANI, Hernán (2005): "La Familia en los 150 Años del Código Civil Chileno", en: Revista Chilena de Derecho. Pontificia Universidad Católica de Chile (Vol. 32, № 3), pp. 431-432.

17 Para una revisión de la evolución de la discusión política sobre esta reforma, HTUN, Mala (2010): Sexo y Estado. Aborto, Divorcio y Familia bajo Dictaduras y Democracias en América Latina (Santiago, Ediciones Universidad Diego Portales), pp. 108-111. Si bien mediante esta reforma la mujer adquiriría una plena capacidad jurídica, el marido continuaba siendo el administrador de los bienes sociales y de los bienes propios de la mujer, situación que afecta el derecho a la igualdad ante la ley constitucionalmente protegido (art. $19 \mathrm{~N}^{\circ} 2$ Constitución, en adelante $\mathrm{CPol}$ ) y que incluso ha motivado el inicio de procesos internacionales destinados a obtener la condena del Estado de Chile. Sobre este punto volveremos en la sección 2.3.

${ }^{18}$ Corral Talcianı, Hernán (1994): “Familia Sin Matrimonio, ¿Modelo Alternativo o Contradicción Excluyente?", en: Revista Chilena de Derecho, Pontificia Universidad Católica de Chile (Vol. 21, № 2), pp. 259-272; CoRral TalCIANI, Hernán (2011): "Matrimonio entre Parejas de un Mismo Sexo. Respuestas a Simposio", en: Anuario de Derechos Humanos (Santiago, Centro de Derechos Humanos, Universidad de Chile), pp. 67-83.

${ }^{19}$ Como ha señalado CARBonnier, en la constitución de la familia, el elemento carnal o biológico ha perdido importancia en beneficio del elemento psicológico y afectivo, pasando la familia a ser concebida ya no como una invisible red unida iure sanguinis, sino como un medio educativo, que no existe más que a condición de ser cotidianamente vivida. CARBOnNIER, Jean (1974): Derecho Flexible. Para una Sociología no Rigurosa del Derecho (traducc. Luis Diez-Picazo, Madrid, Tecnos), pp. 169-170. Con todo, en el Derecho chileno este proceso no es unívoco, pudiendo decirse que existe un renovado 
quienes comparten sus vidas y encuentran en ella un sustento moral y patrimonial irremplazable para su desarrollo personal; encontrándose todo este proceso determinado por la irrupción de un nuevo paradigma en el Derecho privado mismo, definido por los derechos fundamentales (y la noción moral de persona autónoma que a ellos subyace ${ }^{20}$ ) y por el propio cambio que ha existido en las concepciones sociales, particularmente en lo que se refiere al ejercicio de la sexualidad y la forma como las instituciones sociales deben reconocer y valorar las opciones autónomas que cada persona adopta ${ }^{21}$.

Este proceso de reforma de los principios reguladores de la familia chilena reconocería como uno de sus puntos más significativos la reforma de las relaciones paterno-filiales, ocurrido el año 1998 por medio de la Ley № 19.585, que vendría a estructurar los vínculos de filiación conforme al principio de igualdad y al interés superior del niño, eliminando la distinción hasta entonces existente entre hijos legítimos, ilegítimos y naturales ${ }^{22}$, reconociendo los mismos derechos para todos ellos, con una prescindencia casi absoluta acerca de cuál sea el marco que rige la relación de pareja de los progenitores ${ }^{23}$. Con esta reforma, es posible advertir que el legislador chileno cesa en su pretensión de reconocimiento exclusivo de un modelo de familia (legítimamente constituida,

interés por el elemento biológico en lo que concierne a los vínculos de filiación, como consecuencia de la plena recepción del derecho a la identidad.

${ }^{20}$ Peña González, Carlos (1996): "El Derecho Civil en su Relación con el Derecho Internacional de los Derechos Humanos", en: Cecilia Medina Quiroga y Jorge Mera Figueroa (editores), Cuadernos de Análisis Jurídico. Sistema Jurídico y Derechos Humanos. El Derecho Nacional y las Obligaciones Internacionales de Chile en Materia de Derechos Humanos (Santiago, Universidad Diego Portales), pp. 549 y ss. Para una visión crítica sobre el efectivo influjo de los derechos fundamentales en el ordenamiento familiar, TAPIA RodríGuez, Mauricio (2007): "El Caso Chileno: Las Retóricas Declaraciones Constitucionales frente a una Lenta Evolución Social", en: Sebastián Ríos LabBÉ (coordinador), Constitucionalización del Derecho Privado. Actas del Tercer Congreso Internacional de la Association Andrés Bello des Juristes Franco-Latino-Américains (Bogotá, Universidad del Externado), pp. 119-121.

21 Tapia Rodríguez, Mauricio (2007): "El Caso Chileno: Las Retóricas Declaraciones Constitucionales frente a una Lenta Evolución Social", en: Sebastián Ríos LabBé (coordinador), Constitucionalización del Derecho Privado. Actas del Tercer Congreso Internacional de la Association Andrés Bello des Juristes Franco-Latino-Américains (Bogotá, Universidad del Externado), pp. 140 y s.

22 Según el artículo 36 del Código original, los hijos naturales eran una categoría de hijos ilegítimos, caracterizados por el hecho de haber obtenido un reconocimiento por parte de su padre o madre. El Código establecía todavía una categoría adicional, los "hijos de dañado ayuntamiento", donde quedaban comprendidos los hijos adulterinos, incestuosos y sacrílegos, la cual sería derogada por medio de la Ley № 5.750 de 2 de diciembre de 1935.

${ }^{23}$ Véase sobre este punto, Domínguez Hidalgo, Carmen (2005): "Los Principios que Informan el Derecho de Familia Chileno: Su Formulación Clásica y su Revisión Moderna", en: Revista Chilena de Derecho. Pontificia Universidad Católica de Chile (Vol. 32, № 2), pp. 208 y ss.; Cornejo Aguilera, Pablo (2010): "Estatuto Filiativo y Derechos Constitucionales", en: Derecho y Humanidades (№ 16, Vol. 2), pp. 43 61. 
usando la antigua terminología legal) para ampliar la protección hacia otras formas familiares, existentes en la realidad, pero hasta el momento ignoradas o repudiadas por el Derecho.

En efecto, esta transformación en la manera como se estructuran los vínculos de filiación supone no solamente un reconocimiento de la vigencia del principio de igualdad entre todos los niños, sino también de una profundización de la igualdad en las relaciones de pareja, importando un reconocimiento legislativo en orden a que existen múltiples bases sobre las cuales puede estructurarse la familia. Como consecuencia de lo anterior, el matrimonio deja de constituir una institución indispensable para la formación de ésta o para el desarrollo de los vínculos parentales. En último término, este reconocimiento supone, en un plano simbólico, que el matrimonio ya no es el único marco de ejercicio de la sexualidad tutelado por el Derecho ${ }^{24}$, abriéndose de esta forma nuestra legislación a la posibilidad de regular y reconocer las nuevas estructuras familiares que desde hace largo tiempo existían en nuestra sociedad. Este mismo criterio sería posteriormente reiterado en la Ley $\mathrm{N}^{\circ} 19.947$ de matrimonio civil, que en su artículo $1^{\circ}$ inciso $2^{\circ}$ reconoce expresamente la existencia de otras familias, no fundadas en torno a él, al señalar que éste es la base principal (más no exclusiva) de la familia.

Precisamente, este importante paso en la actualización del Derecho de familia chileno sería seguido el año 2004 por la aprobación de la Ley № 19.947 que, a diferencia de su antecesora de 120 años atrás, introdujo importantes modificaciones en la regulación de esta institución, entre las cuales cabe destacar particularmente el reconocimiento del divorcio vincular (art. $42 \mathrm{~N}^{\circ} 4$, extensamente regulado en el Capítulo VI de la ley), tema central en el debate parlamentario. Si bien se trató de una legislación de marcado carácter transaccional, cuya tramitación en el Congreso tomó cerca de 9 años, puede estimarse que el resultado final se aviene bastante bien con las expectativas que la sociedad tenía cifradas en esta nueva regulación, lo que queda reflejado particularmente en las condiciones establecidas para la procedencia del divorcio por cese de la convivencia (forma de divorcio remedio) y en los razonables plazos estipulados

\footnotetext{
${ }^{24}$ Como señalan Fries y MATUS, una de las funciones más relevantes que cumple el matrimonio es la de servir de base para legitimar las relaciones afectivas y el deseo sexual, confiriéndoles un carácter formal e institucionalizado, acorde con las construcciones existentes sobre los roles que cabe desempeñar a hombres y mujeres. Por estas razones, la existencia o no del matrimonio determina un premio o un castigo para los sujetos que se encuentran en esta circunstancia, reflejándose bien este hecho en que nuestro Código civil, hasta el año 1998, si bien establecía la existencia de dos modelos familiares (la familia legítima y la familia ilegítima, con la familia natural como parte de esta última) solamente validaba plenamente a la primera, definiendo a la segunda como su negación, su opuesto, no dotada de una legitimidad en sí misma. Fries, Lorena; Matus, Verónica (1999): El Derecho. Trama y Conjura Patriarcal (Santiago, LOM Ediciones), pp. 103 y ss.
} 
para su procedencia (tres años cuando sea solicitado de manera unilateral por uno de los cónyuges, un año cuando se trate de una petición conjunta de los cónyuges, art. 55 Ley No 19.947).

De esta forma, la nueva regulación chilena refuerza con especial énfasis los elementos asociativos del matrimonio y la individualidad de los cónyuges, para quienes esta institución se presenta como un fundamental recurso simbólico, que define su estatus familiar frente a toda la sociedad, y que además les permite formar un proyecto de vida en común protegido por el ordenamiento ${ }^{25}$, sin Ilegar al extremo que su subsistencia sea protegida independientemente de cual sea su voluntad futura: una vez que desaparece el proyecto de vida en común, el Derecho cesa en la pretensión de subsistencia de la unión y se encarga de reconocer este hecho, regulando sus consecuencias de una manera equitativa ${ }^{26}$.

Sin embargo, es aún posible identificar una segunda mutación en la concepción tradicional de matrimonio, que pone nuevamente énfasis en el carácter asociativo de la unión. En efecto, una de las modificaciones de mayor contenido simbólico introducidas por la nueva normativa matrimonial ocurrió en el plano del tratamiento de la impotencia de uno de los cónyuges, trastorno que en la actualidad no permite per se la declaración de nulidad del matrimonio (a diferencia de lo que ocurría con la ley de 1884, donde era tratada como un impedimento dirimente absoluto, arts. $4^{\circ} \mathrm{N}^{\circ} 3$ y 29 Ley $\left.\mathrm{N}^{\circ} 19.947\right)$, sino solamente fundar una eventual nulidad por error, cuando el otro cónyuge no conociere de esta circunstancia (arts. $8^{\circ} \mathrm{N}^{\circ} 2$ y 46 letra b) ley $\left.\mathrm{N}^{\circ} 19.947\right)^{27}$. De esta manera, la actual regulación matrimonial rompe la otrora necesaria relación entre matrimonio y procreación, estableciendo que la imposibilidad

${ }^{25}$ El matrimonio ocupa un lugar central en todo ordenamiento jurídico moderno pues, como señala AтіYAH, tiene la ventaja de proveer una razón formal para la adopción de múltiples decisiones, las cuales van desde el Derecho de bienes, hasta las sucesiones. AтıYAH, Patrick S. (1986): Essays on Contract (Oxford, Oxford Clarendon Press), p. 107.

${ }^{26}$ Sobre este punto, considérese especialmente la emergencia en el Derecho de familia del principio de la protección del cónyuge más débil y su aplicación al momento de la terminación del matrimonio. Sobre el tema, consúltese Lepín Molina, Cristian (2012): "La Autonomía de la Voluntad y Protección del Cónyuge Más Débil en la Determinación y Pago de la Compensación Económica", en: Revista lus et Praxis, Universidad de Talca (Año 18, № 1), pp. 3-36.

${ }^{27}$ Con todo, esta interpretación no es unánime en Chile: existe un sector de la doctrina que, desatendiendo la historia fidedigna de la ley de matrimonio civil y contrariando la lógica del sistema de sanciones civiles, ha propuesto que en estos casos el matrimonio celebrado sería en realidad inexistente, al mantenerse la finalidad procreativa en la definición de matrimonio que proporciona el artículo 102 del Código civil. Corral Talciani, Hernán (2009): "Sentido y Alcance de la Definición de Matrimonio del Artículo 102 del Código Civil, Después de la Introducción del Divorcio Vincular por la Ley № 19.947, de 2004", en: Revista Chilena de Derecho, Pontificia Universidad Católica de Chile (Vol. 36, № 1), p. 71; Corral Talcianı, Hernán (2011): Separación, Nulidad y Divorcio. Análisis desde los Principios y las Reglas de la Ley de Matrimonio Civil (Santiago, Abeledo-Perrot), pp. 17-18. 
objetiva de consecución de uno de los fines todavía declarados por el artículo 102 CC no permite privar al matrimonio de sus efectos, sino en la medida que esta anomalía, siendo ignorada por el otro cónyuge, le impida realizar sus proyectos de vida, los cuales lo llevaron a contraer matrimonio.

Conforme a lo expuesto, podemos afirmar que en las últimas décadas el ordenamiento jurídico chileno ha enfrentado profundas transformaciones en todo lo que concierne a la regulación del Derecho de familia, suponiendo estos cambios una completa alteración de los principios que subyacen a esta normativa. Así, hemos pasado de encontrarnos regido por un Derecho de familia inspirado en los principios de protección de la familia legítima, estructuración jerarquizada de las relaciones de familia y protección reforzada del vínculo matrimonial, a reconocer la pluralidad de formas en que esta entidad puede organizarse, siempre en un marco regido por la igualdad y el mutuo respeto entre sus miembros. Como bien lo consigna el profesor TAPIA, el Derecho chileno asume, cada vez más, una noción de familia cercana a aquella identificada por el Decano CARBONNIER como característica de las sociedades modernas, donde ésta aparece antes como un instrumento entregado a cada uno para el desarrollo de su personalidad, dejando el Derecho civil de trazar normativamente un modelo de vida, y pasando a preocuparse simplemente de remediar los conflictos (personales y patrimoniales) que surgen cuando se frustran estos proyectos familiares ${ }^{28}$.

\section{Desafíos actuales del Derecho de familia en Chile. Principales Reformas}

Sin embargo, y pese al amplio alcance de las modificaciones introducidas por las leyes $\mathrm{N}^{\circ}$ s. $18.802,19.335,19.585$ y 19.947 , esta tarea de actualización del Derecho de familia parece todavía inconclusa: prueba de ello son las demandas de reconocimiento y protección de otras realidades, que hoy no dudaríamos en calificar de familiares, como ocurre con la convivencia entre personas de distinto y del mismo sexo; a lo cual se suma la necesidad de eliminar los últimos vestigios todavía existentes de la antigua legislación fundada sobre una distribución de roles hoy considerada obsoleta, donde el marido

${ }^{28}$ Tapia RodríGuez, Mauricio (2008): "Del Derecho de Familia Hacia un Derecho de las Familias", en: Alejandro Guzmán Brito (Editor), Estudios de Derecho Civil III. Jornadas Nacionales de Derecho Civil. Valparaíso, 2007 (Santiago, Abeledo-Perrot), p. 161. En el mismo sentido, señala la profesora Domínguez que "El prisma actual desde el cual se mira a la familia ha variado, centrándose en el presente más en los individuos que la componen que en la entidad familiar misma". Domínguez Hidalgo, Carmen (2005): "Los Principios que Informan el Derecho de Familia Chileno: Su Formulación Clásica y su Revisión Moderna", en: Revista Chilena de Derecho. Pontificia Universidad Católica de Chile (Vol. 32, № 2), p. 214. 
aparecía no sólo como el proveedor, sino también como el nexo entre la familia y el ámbito público, mientras a la madre correspondía un dominio sobre el ámbito doméstico, reflejado particularmente en la maternidad y la crianza de los hijos, modelo cuya subsistencia resulta contraria a la igualdad reconocida en el artículo $19 \mathrm{~N}^{\circ} 2 \mathrm{CPol}^{29}$. Cada una de estas demandas han generado el inicio de distintos procesos legislativos: mientras la primera de ellas ha sido recogida en el proyecto de acuerdo de vida en pareja (Boletín $N^{0}$ 7873-07), las segundas se han reflejado en los proyectos de reforma de la sociedad conyugal (Boletines $N^{\circ}$ 7567-07 y 7718-18) y en los que buscan establecer una efectiva corresponsabilidad parental (Boletines No 5917-18 y 7007-18). Cada una de estas reformas será analizada por separado en las secciones siguientes.

\section{Acuerdo de vida en pareja}

Como se ha expuesto en la primera parte de este trabajo, la familia, cualquiera sea la forma que ésta adopte, constituye un espacio personalísimo de asociación, el cual, fundado en la existencia de una especial afectividad entre sus miembros ${ }^{30}$ e inspirada en el mutuo respeto, solidaridad y consideración entre éstos, proporciona a cada uno de ellos un soporte moral y material insustituible, hasta tal punto, que es posible afirmar que no existe otra institución en la cual podamos encontrar los bienes que nos proporciona. La familia constituye un espacio en el cual desarrollamos una parte principal de nuestro plan de vida, hecho que es reconocido por el Pacto Internacional de Derechos Civiles y Políticos (art. 23.2) y por la Convención Americana de Derechos Humanos (art. 17.2), que consagran el derecho fundamental de cada persona a contraer matrimonio y a fundar una. En términos generales, son tantos los beneficios

\footnotetext{
${ }^{29}$ En situaciones de crisis familiar, por regla general correspondía que el hijo legítimo permaneciera junto a su padre, a menos que fuere menor de 5 años. Esta regla sería objeto de sucesivas modificaciones: la primera, en 1935, mediante la Ley $N^{\circ}$ 5.680, aumentó la edad a 10; materia que sería nuevamente reformada por la Ley $\mathrm{N}^{\circ} 10.271$, hasta alcanzar los 14 años. Finalmente, la Ley № 18.802 de 1989 terminaría por establecer la regla inversa, disponiendo que, en caso que los padres vivan separados, el cuidado de los hijos menores corresponderá a la madre.

${ }^{30}$ Según señala la profesora TURNER, Como consecuencia de la irrupción de la afectividad en el ámbito del Derecho se produce un acercamiento entre las uniones de hecho y el matrimonio, adquiriendo el carácter de razón justificativa de su especialidad y de la necesidad de conferirles respuestas legales a sus intereses. Turner Saelzer, Susan (2010): "La Unión de Hecho como Institución del Derecho de Familia y su Régimen de Efectos Personales", en: Revista lus et Praxis, Universidad de Talca (Año 16, $N^{\circ} 1$ ), p. 90. En nuestro concepto, esta afectividad es un elemento propio de la realidad familiar, que se expresa en la coincidencia existente entre los miembros de la unión en orden a estar compartiendo sus destinos, de estar formando un proyecto de vida en común; y que permite distinguir claramente la situación de los convivientes de la que existe entre simples amigos que comparten un techo en común, o de otras nuevas realidades que han comenzado a ser reguladas en el Derecho comparado, como ocurre con las situaciones convivenciales de ayuda mutua y con las familias de acogida.
} 
asociados a su existencia, que resulta particularmente gravoso e incomprensible excluir a determinadas personas de su goce, o negar legislativa o judicialmente el reconocimiento y protección que nuestra Constitución asegura a algunas de las formas que esta realidad puede adoptar. En el caso chileno, este importante argumento de principio se ve complementado por una imperiosa necesidad de política pública, reflejada en la existencia de más un millón de parejas que han optado por construir su vida familiar al margen del matrimonio ${ }^{31}$, recurriendo a la convivencia, las cuales hasta el momento no gozan de un estatuto de protección propio ${ }^{32}$.

Son precisamente estas razones las que justificaron la presentación por parte del Ejecutivo del proyecto de ley que establece la figura del acuerdo de vida en pareja (Boletín $\mathrm{N}^{\circ} 7873-07$, en adelante AVP33). En efecto, según señala el Mensaje, fue el reconocimiento de la convivencia como uno de los sustratos fundadores de la familia, y por lo tanto, como una realidad digna de respeto y consideración por parte del Estado, que mira a las importantes funciones que a ésta le corresponde desarrollar, y a los beneficios que su existencia implica, tanto para las personas que la componen, como para la sociedad en general, lo que motivó la presentación del proyecto de ley, que pone especial énfasis en el hecho que a la celebración del acuerdo subyace una realidad que permite compartir el amor, los afectos y vivir la intimidad, al tiempo que confiere a sus miembros un apoyo emocional y material fundamental para el desarrollo de sus propios planes de vida. Como puede apreciase, las descritas por el Ejecutivo son precisamente aquellas ventajas sociales atribuidas por las visiones tradicionales del Derecho en forma exclusiva al matrimonio, significando ciertamente este

\footnotetext{
31 Según las cifras que arrojó el último censo de población realizado en el país durante el año 2012, en Chile existen 2.078 .727 parejas de convivientes de distinto sexo y 34.976 parejas de convivientes del mismo sexo. La información se encuentra disponible en: InSTItUTO NACIONAL DE Estadísticas, http:// www.censo.cl [visitado el 29/04/2013].

${ }^{32}$ Con todo, existen ciertas soluciones jurisprudenciales que, desarrollándose a partir de criterios propios del Derecho civil patrimonial, como la comunidad y la sociedad de hecho, han proporcionado cierta protección a los miembros de la pareja después del fin de su relación, sobre todo cuando este hecho se produce como consecuencia de la muerte de uno de ellos. En principio, estas soluciones resultarían también aplicables a las parejas del mismo sexo. Sobre el punto, Donoso Vergara, María Florencia; RıoseCO LÓPEZ, Andrés (2008): El Concubinato ante la Jurisprudencia (Santiago, Legalpublishing); de la BarRa Suma de VILLA, María Asunción (2010): "Breve Análisis Normativo sobre Uniones de Hecho en la Legislación Chilena: Posibilidad de Aplicación a Parejas Homosexuales", en: Derecho y Humanidades ( $N^{\circ} 16$, Vol. 2), pp. 101-117. Para una revisión general de la legislación referida a las uniones de hecho en Chile, Barrientos Grandón, Javier (2009): De las Uniones de Hecho. Legislación, Doctrina y Jurisprudencia (Santiago, Legalpublishing).

33 Por acuerdo de la Comisión de Constitución, Legislación y Justicia del Senado, este proyecto de ley está sometido a tramitación conjunta con el proyecto de "acuerdo de vida en común" presentado por los entonces senadores AlLamand y Chadwick (Boletín № 7011-07).
} 
primer reconocimiento, en el plano simbólico, un avance para la protección de todas las familias ante la ley.

Por la lógica que inspira al proyecto, creemos que la aprobación del AVP significará un nuevo avance en lo que se refiere a la regulación de las relaciones de pareja, que pretende por vía de la creación de una nueva institución, paralela y distinta del matrimonio, proveer a las personas que deciden conformar un proyecto de vida en común de un marco destinado a regular las consecuencias patrimoniales de su relación. Sin embargo, por más que el proyecto esté centrado en torno a este primer elemento, es imposible desconocer el hecho que las ventajas que presenta el AVP en el plano de la regulación de las relaciones de familia no se limitan a proporcionar protección a los miembros de la pareja. Por el contrario, la introducción del AVP en la legislación chilena supondrá, desde un plano simbólico, una afirmación intensificada del principio de igualdad en la regulación de las relaciones de pareja, como consecuencia del carácter doblemente igualitario que presenta esta institución: el AVP, además de disponer de un marco regulatorio al cual tendrán acceso tanto las parejas de distinto como del mismo sexo, no impone a sus miembros determinados derechos y deberes sobre la base de una marcada distribución de roles, según cual sea su género. Es por esta razón que, en este segundo sentido, la aprobación del AVP puede suponer un importante desafío para la regulación matrimonial, desde el momento que pondrá en evidencia las contradicciones que esta última presenta frente a los principios que rigen la comprensión actual de las realidades familiares ${ }^{34}$.

Sin embargo, este mismo carácter igualitario genera importantes problemas técnicos al momento de definir cuál será el contenido de esta nueva regulación, dificultades que derivan de la tensión existente a causa de los disímiles intereses que pueden ser observados, según si se trate de parejas de distinto o del mismo sexo. En este sentido, no puede olvidarse que, mientras para las parejas de distinto sexo, que pueden acceder el día de hoy a la institución matrimonial, el contenido de la nueva regulación debería considerar el establecimiento de claras diferencias con aquella institución que no es utilizada, tanto en lo que

\footnotetext{
${ }^{34}$ En este sentido, es esperable que la aprobación del acuerdo suponga un ejercicio de lo que ESKRIDGE Jr. ha calificado como "igualdad transformadora", que sobre la base del respeto de las diferencias, nos proporcione una oportunidad para reflexionar sobre la justicia de las prácticas pasadas, con la finalidad de rediseñar las instituciones de tal manera que sean mejores para la sociedad en su conjunto. ESKRIDGE Jr. William (1999): "La Discusión sobre el Matrimonio entre Personas del Mismo Sexo y Tres Concepciones de Igualdad", en: Revista Jurídica de la Universidad de Palermo (Buenos Aires, Universidad de Palermo), pp. 203-229. Disponible en:

http://www.palermo.edu/derecho/publicaciones/pdfs/revista_juridica/Especiales_SELA/SELA\%20 1999\%20-\%20Ed\%202000/04SELA99]uridica11.pdf [visitado el 29/04/2013]. Por su importancia, destacan particularmente los desafíos en materia de relación paterno-filial y de régimen de bienes, las cuales están siendo actualmente objeto de debate y que serán analizadas en las dos secciones siguientes.
} 
concierne a la forma de su celebración como a sus efectos; para las parejas de distinto sexo, que en la actualidad no cuentan con otra forma de reconocimiento de su relación, resulta relevante el establecimiento de una figura que les proporcione un acto que marque simbólicamente el inicio de su relación, por todas las implicancias de validación social que le están asociadas, al tiempo que presente un contenido que sea lo más denso posible.

En el proyecto de ley esta primera problemática se resuelve, correctamente a nuestro juicio, estableciendo que el AVP tiene por objeto regular las consecuencias jurídicas que se derivan de la vida afectiva en común, entendiéndose por tales, de acuerdo al desarrollo del proyecto de ley, aquellas referidas al ámbito patrimonial de la pareja. Esto marca una importante diferencia con el matrimonio, institución cuya regulación no sólo se refiere a los aspectos patrimoniales de la vida en común, sino que incorpora importantes elementos de naturaleza ética y carácter indudablemente familiar, los cuales quedan comprendidos en las relaciones personales entre los cónyuges. De esta forma, mientras en el matrimonio es posible identificar los deberes de fidelidad, de socorro, de ayuda mutua, de respeto y protección recíproca, de vivir juntos, de cohabitación y de expensas para la litis ${ }^{35}$, todos los cuales pertenecen intrínsecamente a esta institución y resultan indisponibles para los cónyuges, dado que se encuentran estrechamente vinculados a la idea de comunidad o consorcio de vida que se genera entre ellos con el matrimonio, en el AVP solamente será posible encontrar un genérico deber de ayuda mutua y una obligación de contribuir a solventar los gastos generados por la vida en común (art. $7^{\circ}$ Proyecto, en adelante PrAVP), el cual está estrechamente vinculado con los efectos patrimoniales del acuerdo, hecho que se confirma por su ubicación sistemática en el Título II del proyecto ${ }^{36}$.

Ahora bien, contrariamente a lo que puede pensarse, los efectos de esa diferencia no quedan reducidos al ámbito de los principios, sino que afectan la manera misma como se concibe la institución. Así, en un estatuto marcadamente contractual como es el AVP, resulta coherente que su aplicación cese cuando las partes de común acuerdo decidan poner término al acuerdo (art. $6^{\circ}$ letra d) PrAVP), o que incluso se reconozca como causal de término la declaración unilateral de voluntad que realice una de ellas, derecho característico de las relaciones contractuales de duración indefinida (art. $6^{\circ}$ letra e) PrAVP), régimen libre de terminación que pugnaría con la estabilidad que demanda el vínculo matrimonial y el consorcio de vida que se forma con su celebración. En nuestro concepto, es éste precisamente el punto central

\footnotetext{
${ }^{35}$ Código civil, Libro I, Título VI, párrafo $1^{\circ}$.

36 Título que gráficamente lleva por epígrafe "De los efectos patrimoniales del acuerdo de vida en pareja".
} 
que permitirá diferenciar a ambas instituciones, dotando a cada una de ellas de una individualidad propia dentro del Derecho de familia, constituyendo un límite que no podría ser afectado por el legislador, so riesgo de afectar la posición prominente que tiene el matrimonio como forma de regulación de la relación de pareja y base de la familia ${ }^{37}$.

Lo señalado anteriormente no significa que el nuevo estatuto deba excluir cualquier regulación que escape al ámbito patrimonial, máxime si consideramos que la realidad de base que está siendo regulada es familiar. Este hecho exige moderar los efectos puramente contractuales del acuerdo, como de hecho el proyecto lo hace, al reconocer derechos hereditarios al contratante superviviente $^{38}$ y, como creemos, debería hacerse incorporando reglas sobre parentesco por afinidad, a fin de impedir que el AVP sea un instrumento que sirva para legitimar relaciones que podrían calificarse de "incestuosas" 39 , como aquella que nazca entre el hijo/hija de uno de los contratantes y el otro miembro de la pareja que, pese a no ser su padre o madre, ha desarrollado un rol parental o cuasi-parental en el seno de esa familia. Conforme a las reglas actuales del proyecto, siendo ambos extraños absolutos, se encuentran en una posición donde nada impide que puedan celebrar en el futuro un AVP (o incluso, de existir diferencia de sexo, un matrimonio), situación que creemos debe ser remediada durante el debate parlamentario.

En los términos expuestos, queda todavía por responder dos cuestiones. ¿Implica la aprobación del AVP una desprotección o afectación del matrimonio? Siendo ambas instituciones claramente distintas, no somos capaces de advertir de qué forma la aprobación del primer estatuto produciría un efecto

\footnotetext{
${ }^{37}$ Por el contrario, estimamos que una modificación del matrimonio que permita, por ejemplo, su terminación libre, desnaturalizaría de tal forma la institución que la tornaría irreconocible, afectando de esa manera la garantía institucional del matrimonio e, indirectamente, el derecho a contraer matrimonio, reconocido en los artículos 23 del Pacto Internacional de Derechos Civiles y Políticos y 17 de la Convención Americana de Derechos Humanos.

${ }^{38}$ Conforme a lo establecido en el artículo $9^{\circ}$ PrAVP, en aquellos casos en que el acuerdo hubiese tenido una duración mínima de un año, "el contratante sobreviviente concurrirá con los hijos del causante, recibiendo una porción que será igual a lo que, por legítima rigorosa o efectiva, corresponda al hijo o a cada hijo si fueren más de uno. Si el causante no ha dejado descendencia, le sucederán el contratante sobreviviente y sus ascendientes de grado más próximo. En este caso, la herencia se dividirá en dos partes iguales, una para el contratante sobreviviente y la otra para los ascendientes. A falta de estos últimos, llevará todos los bienes el contratante sobreviviente, y, a falta de contratante, los ascendientes". Como puede apreciarse, el proyecto confiere al contratante supérstite la calidad de heredero legal en la sucesión de su pareja, mas le niega el carácter de heredero forzoso o legitimario. Por su parte, el artículo $10^{\circ}$ PrAVP se encarga de establecer que en los casos de sucesión testamentaria, el contratante supérstite puede ser beneficiado con todo o parte de la "cuarta de mejoras", supeditando esta posibilidad al mismo plazo establecido en el artículo $9^{\circ}$ PrAVP.

${ }^{39}$ Grosman, Cecilia P.; Martínez Alcorta, Irene (2000): Familias Ensambladas. Nuevas Uniones Después del Divorcio (Buenos Aires, Editorial Universidad), pp. 150-155.
} 
negativo sobre el segundo. En último término, el problema de los incentivos para contraer matrimonio dice relación con las ventajas que estén asociadas a esta institución, no con impedir el reconocimiento y protección de otras formas de hacer familia ${ }^{40}$. ¿Es la aprobación del AVP el primer paso para el reconocimiento del matrimonio igualitario? La propia diferencia entre las instituciones hace que se trate de discusiones completamente diversas, construidas sobre premisas diferentes: mientras la discusión sobre el matrimonio igualitario gira en torno al acceso igualitario a una institución social, confirmando su posición central en el Derecho de familia, la discusión sobre el AVP lo hace sobre la necesidad de crear un Derecho más pluralista, que desarrolle instituciones capaces de dar reconocimiento y protección a las nuevas realidades familiares ${ }^{41}$.

Habiéndonos referido a las particularidades que presenta el acuerdo frente al matrimonio, y los límites que debería atender un proyecto que reconozca y proteja esta realidad familiar subyacente, corresponde tratar el otro extremo: la relación existente entre el AVP y las uniones de hecho. ¿Qué modelo de protección debe seguir el legislador? ¿Un modelo factual o un modelo formal? Con todo, antes de iniciar el análisis, creemos necesario hacer una prevención inicial: la adopción de un modelo factual o de un modelo formal de regulación no ha sido, en la práctica, irrelevante, desde la perspectiva del contenido previsto por cada legislador ${ }^{42}$.

La diferencia existente entre estos dos modelos de regulación ha sido bien expuesta por la profesora Domínguez LozANo, quien explica que "las soluciones que responden al modelo fáctico sólo implican la ordenación legal de ciertos derechos y efectos vinculados a la convivencia estable; sin crear, a diferencia de un modelo formal, una figura legal, cuyo contenido pueda configurar un

\footnotetext{
${ }^{40}$ Resulta destacable en este sentido constatar que la experiencia francesa demuestra que la aprobación de un estatuto formal para los convivientes expande el número de parejas protegidas por el ordenamiento, en una medida muy superior a la disminución del número de matrimonios: así, mientras el año 2000 se celebraron 305.234 matrimonios y 16.859 PaCS entre personas de distinto sexo, sumando un total de 322.093 parejas acogidas a alguna formal de regulación, el año 2010 el número de matrimonios había bajado a 251.654, siendo esta cifra más que compensada por el espectacular aumento del número de PaCS celebrados, que ese año totalizó 196.415, para sumar un total de 448.069 parejas acogidas a alguna forma de regulación. Como se puede inferir de las cifras entregadas, el PaCS más que desincentivar la celebración de matrimonios, llevó a un número importante de convivientes a formalizar su relación. Información disponible en: Institut National de la Statistique et des Études Économiques, http://www.insee.fr/fr/themes/tableau.asp?reg_id=0\&ref_id=NATTEF02327 [visitado el 29/04/2013].

${ }^{41}$ Sobre la temática del matrimonio igualitario en Chile volveremos al final de este documento.

42 Para un análisis de las consecuencias que se derivan de la convivencia frente al matrimonio y las uniones registradas, WAaldiJK, Kees y Fassin, Éric (2008): Droit Conjugal et Unions de Même Sexe. Mariage, Partenariat et Concubinage dans Neuf Pays Européens (Paris, Presses Universitaires de France).
} 
nuevo status jurídico para los particulares. De tal manera que bajo el modelo fáctico la unión de pareja sigue siendo 'unión de hecho', mientras que bajo el modelo formal la unión de pareja se transforma en 'unión de derecho'; manteniéndose en ambos casos, eso sí, como uniones extramatrimoniales". ${ }^{43}$ Acorde con lo expuesto, es posible distinguir en lo que se refiere a las condiciones de aplicabilidad de un estatuto de pareja entre dos modelos: aquellos que crean un estatuto formal, cuyo perfeccionamiento depende del cumplimiento de una determinada solemnidad, que hace las veces de condición necesaria para el desarrollo de las consecuencias jurídicas previstas por la ley, como puede ser el registro de la unión de pareja en una oficina determinada o su celebración ante un oficial público; y aquellos que vienen a regular una situación de facto, condicionando la atribución de determinados efectos jurídicos a la existencia de un hecho, como es la convivencia.

Entre estas dos alternativas posibles, el AVP se inclina por la creación de un estatuto formal ${ }^{44}$, lo que se expresa especialmente en la regulación de las formas de celebración del acuerdo: conforme a lo dispuesto en los artículos $3^{\circ}$ y $4^{\circ}$ del Proyecto, el AVP puede ser celebrado ante el oficial civil o a través de una escritura pública otorgada ante Notario; a lo cual se agrega un requisito adicional, cual es la inscripción de la escritura o del acta dentro del término de 10 días hábiles contados desde su otorgamiento en el registro especial de acuerdos de vida en pareja que llevará el Servicio de Registro Civil. Con el fin de reforzar el carácter de solemnidades que tienen las formalidades descritas, el artículo $5^{\circ}$ del proyecto se encarga de establecer que, en caso que no se proceda a la inscripción del acta o de la escritura, según corresponda, el AVP no desarrollará efectos, ni entre las partes, ni respecto de terceros.

Ciertamente, la adopción de esta solución legislativa puede ser criticada por quienes consideran que esta regulación alternativa debe construirse en torno a un hecho, como es la sola existencia de la convivencia, bien sea porque en nuestro país el no acceso a la institución matrimonial no se produce como consecuencia de un repudio ideológico al matrimonio como forma de organizar la familia, sino simplemente por la existencia de una realidad que se encuentra en los márgenes del Derecho, que no es alcanzada por sus mandatos (como lo

${ }^{43}$ Domínguez Lozano, Pilar (2006): "Las Uniones de Personas del Mismo Sexo: Las Opciones de Regulación y sus Implicancias Jurídicas", en: Derecho Privado y Constitución (Madrid, Centro de Estudios Políticos y Constitucionales, No 20), p. 184.

${ }^{44}$ En la regulación propuesta por el Ejecutivo, la única excepción es la referida a los derechos hereditarios del miembro de la pareja sobreviviente, los cuales están supeditados a que el acuerdo hubiere durado a lo menos un año (art. $9^{\circ}$ ), solución que nos parece sumamente criticable, por romper la lógica conforme a la cual se estructura el sistema y por no guardar relación con los fines perseguidos. Para evitar que el acuerdo sea usado para defraudar las expectativas de los legitimarios basta con las acciones de nulidad. 
ha hecho en nuestro medio el profesor $\mathrm{VARAS}^{45}$ ); bien sea porque, en sí misma, la decisión adoptada por una pareja en orden a convivir debe entenderse como expresión de un deseo de formar una vida en conjunto, satisfaciéndose de esa forma el sustento de base que legitima la intervención del legislador (como ha argumentado la profesora ESPADA ${ }^{46}$ ). Si bien reconocemos que se trata de críticas acertadas, que no pueden ser desatendidas al momento de definir cuál será la regulación chilena en la materia, creemos que la solución a la problemática planteada no pasa por establecer un estatuto factual, en remplazo del estatuto formal actualmente contemplado en la regulación del AVP, existiendo buenas razones, más allá de la especial problemática de validación que concierne a las parejas del mismo sexo, para mantener una visión formalizada como la recogida actualmente en el proyecto, las cuales se relacionan, en términos generales, con el rol de las formalidades en el Derecho ${ }^{47}$.

En efecto, en esta materia el formalismo no sólo desarrolla las funciones simbólicas propias de la celebración de un rito de inicio de la conyugalidad. Por el contrario, existen importantes razones de seguridad jurídica que imponen la existencia de un estatuto formal, lo que se refleja particularmente en la necesidad de que exista un medio conclusivo de poder determinar la existencia de la unión frente a terceros y el Estado. Para poder apreciar los alcances que desarrollan las formalidades en esta materia, podemos simplemente preguntarnos ¿De qué otra forma pueden los terceros tener noticia de su existencia al

\footnotetext{
${ }^{45}$ Según señala el profesor VARAS: "Como ya se avanzó, lo anterior significa, a mi juicio, que en Chile la resistencia al matrimonio no era mayoritariamente, como pudiera haberse pensado, ideológica o técnica. [...] Si esto es así, entonces pueden colegirse una tríada de consecuencias que parece necesario explicitar. Primera, que la dictación de una ley basada en la celebración de un rito formal (cual que sea) no va a solucionar el problema social que representan las convivencias afectivas terminadas, sea por ruptura, sea por muerte de uno de los convivientes. Al menos, está claro que no va a resolver el problema de quienes necesitan de modo más agudo la intervención estatal: los más pobres, los de menor educación, los de menos oportunidades. Porque si los excluidos se marginan del matrimonio, con todo el prestigio social que tiene esta institución, no se divisa razón por la cual vayan a concurrir a celebrar un contrato diverso a una Notaría o a otra oficina pública, y luego a registrarlo a otra diversa". Varas Braun, Juan Andrés (2011): "Uniones de Hecho: Constitución y Prueba", en: Estudios de Derecho Civil VI. Jornadas Nacionales de Derecho Civil. Olmué 2010 (Santiago, Editorial Abeledo-Perrot), p. 67.

${ }^{46}$ Espada Mallorquín, Susana (2007): Los Derechos Sucesorios de las Parejas de Hecho (Pamplona, Editorial Thomson Civitas), pp. 78-89; EsPada Mallorquín, Susana (2009): "El Reconocimiento de Derechos Sucesorios a las Parejas de Hecho en España", en: Revista Chilena de Derecho Privado, Fundación Fernando Fueyo (No 12), pp. 14-24.

${ }^{47}$ El razonamiento que sigue está fundado en la exposición hecha por Patrick S. ATIYAH en torno a la forma y la sustancia en el Derecho. Sobre el punto, revisar especialmente AtiYAH, Patrick S. y SUMmeRS, Robert S. (1987): Form and Substance in Anglo-American Law. A Comparative Study on Legal Reasoning, Legal Theory, and Legal Institutions (Oxford, Oxford Clarendon Press), pp. 1-41; AтাYAH, Patrick S. (1986): Essays on Contract (Oxford, Oxford Clarendon Press), pp. 93-120.
} 
momento de celebrar un contrato? ¿Cómo poder determinar qué convivencia de hecho será relevante para efectos de conceder al miembro de la pareja sobreviviente derechos sucesorios? O como se planteaba el profesor GarRIDO Melero, a propósito de la aplicación de la Ley No 10/1998 de Cataluña, ¿cómo podemos determinar, por ejemplo, que la unión de hecho ha sido ininterrumpida o ha llegado definitivamente a su fin? ${ }^{48}$ Todos estos problemas son solucionados de una manera simple cuando existe una formalidad, caso en el cual nos basta con constatar la existencia del acto que da origen para poder responder todas las preguntas planteadas, liberando a los aplicadores del Derecho de la necesidad de tener que atender a criterios sustanciales, de difícil apreciación, para efectos de poder definir cuándo una pareja estará o no protegida ${ }^{49}$.

Con todo, sin perjuicio de lo expuesto precedentemente, creemos importante que durante la discusión parlamentaria se considere la inclusión de una regla a la manera del artículo 515-8 del Code civil francés, a fin de validar los desarrollos jurisprudenciales realizados con la finalidad de proteger a los miembros de las uniones de hecho o convivencias desformalizadas, atendido su carácter de realidades familiares dignas de protección ${ }^{50}$, e idealmente, in-

${ }^{48}$ Garrido Melero, Martín (1999): Derecho de Familia. Un Análisis del Código de Familia y de la Ley de Uniones Estables de Pareja de Cataluña y su Correlación con el Código Civil (Barcelona, Marcial Pons Ediciones Jurídicas y Sociales), p. 90. En este sentido, resulta particularmente elogiable que el Proyecto no contemple como causal de término "la declaración judicial de cese de la convivencia, a petición de cualquier que tenga intereses sucesorios", prevista en el art. $14 \mathrm{~N}^{\circ} 6$ del proyecto de acuerdo de vida en común.

${ }^{49}$ Puede realizarse perfectamente una analogía con las funciones que desarrollan las formalidades en el matrimonio. AтіYAн, Patrick S. (1986): Essays on Contract (Oxford, Oxford Clarendon Press), pp. 105-107. Sobre el mismo punto, señala la profesora TURNER que "El ordenamiento jurídico utiliza el matrimonio, más específicamente, su formalidad, para obtener a partir de él certezas necesarias para la vida social y que, por regla general, coinciden con la realidad". Turner SAeLzer, Susan (2005): "Comentario Sentencia sobre los Efectos de la Terminación de una unión More Uxorio y su Relación con un Régimen Patrimonial Matrimonial Vigente (Corte Suprema)", en: Revista de Derecho, Universidad Austral, Valdivia (Vol. XVIII, № 2), pp. 233-244.

${ }^{50}$ Sobre este punto, han señalado las profesoras MARTINIC y WEINSTEIN que "El ordenamiento jurídico está obligado a amparar a quien pueda resultar perjudicado con la unión libre, estableciendo consecuencias jurídicas que lo favorezcan, trátese de los hijos, de los terceros o de la parte más débil de la relación conyugal de hecho, que puede quedar abandonada a su suerte después de una larga convivencia". Martinic Galetovic, María Dora y Weinstein Weinstein, Graciela (2004): "Nuevas Tendencias de las Uniones Conyugales de Hecho", en: Instituciones de Derecho de Familia (Santiago, Editorial LexisNexis), p. 17. En relación con la posibilidad de regulación de las relaciones de pareja, frente al derecho a contraer matrimonio, ha señalado la profesora ESPADA, en una argumentación que comparto, que "el libre desarrollo de la personalidad y la libre elección de no casarse no se vulneran cuando la resolución de los conflictos típicos de la convivencia more uxorio se realiza acudiendo a ciertas normas matrimoniales. La faceta negativa del derecho a casarse garantiza que nadie puede imponer a un sujeto la institución matrimonial, pero no reconoce a este sujeto un derecho a que no se regulen sus conflictos. De tal forma que, si la solución que el ordenamiento jurídico da a ciertos conflictos típicos que surgen de la convivencia matrimonial es aplicable por analogía a los conflictos que surgen de la 
corporar ciertas reglas mínimas que se encarguen de regular la situación en que quedan una vez producida la ruptura ${ }^{51}$, y otras que les permitan acceder a beneficios proporcionados por el Estado o que se encuentran dentro del ámbito de la seguridad social.

\section{Régimen de bienes del matrimonio: la reforma de la sociedad conyugal}

Como anticipáramos, la primera demanda de igualdad que se ha formulado a la actual regulación familiar chilena se refiere a la modificación de la sociedad conyugal, régimen de bienes que, no obstante la reforma de 1989, sigue dejando a la mujer en una posición desmedrada respecto de su marido, atendido el hecho que la ley le niega la posibilidad de ser designada como la administradora ordinaria de la sociedad conyugal y a que, incluso, pierde la administración de sus bienes propios, circunstancia que llega a constituir una verdadera incapacidad encubierta. Sin embargo, para poder comprender las razones que exigen su reforma, es necesario hacer previamente unos breves comentarios generales sobre la sociedad conyugal y su relación con los otros regímenes de bienes.

En la actualidad, la legislación chilena reconoce solamente una autonomía limitada a los cónyuges al momento de definir cuál será el régimen de bienes al cual se someterán durante su matrimonio ${ }^{52}$, contemplando la existencia de tres sistemas, cada uno de ellos estructurado según sus propias reglas: la sociedad conyugal, régimen que pone énfasis en las ideas de comunidad de vida y solidaridad entre los cónyuges, cuyo funcionamiento implica la formación de diversos patrimonios para administrar los bienes que les pertenezcan al momento de la celebración del matrimonio, o que adquieran con posterioridad ${ }^{53}$,

convivencia more uxorio, los sujetos no están amparados por la faceta negativa del derecho a casarse para excluir la aplicación de la resolución de esos conflictos". EsPADA MALLORQuín, Susana (2007): Los Derechos Sucesorios de las Parejas de Hecho (Pamplona, Editorial Thomson Civitas), pp. 88-89.

${ }^{51}$ Como el reconocimiento de derechos sucesorios de carácter limitado o bien el establecimiento de un derecho real de uso respecto de la vivienda donde se haya desarrollado la vida familiar, la validación de la regla que confiere legitimación activa para demandar perjuicios en muerte accidental de su compañero, etc.

52 En general sobre el tema, véase Schmidt Hотт, Claudia (1999): "Régimen Patrimonial y Autonomía de la Voluntad", en: Revista Chilena de Derecho. Pontificia Universidad Católica de Chile (Vol. 26, №1), pp. 105-119; Ramos Pazos, René (2007): Derecho de Familia, Sexta Edición Actualizada (Santiago, Editorial Jurídica de Chile), tomo I, pp. 146-348.

${ }^{53}$ Como explica la profesora Gatıca: "Desde el punto de vista de su titularidad, el régimen de sociedad conyugal reconoce dos clases de bienes: los sociales y los propios de cada cónyuge. El patrimonio social se compone de dos partidas: el haber absoluto - al cual ingresan los bienes de manera definitiva y corresponde a los cónyuges por partes iguales al momento de la liquidación del régimen-y el haber relativo -al cual ingresan los bienes de manera 'temporal', en el sentido de que generan un derecho para el cónyuge que los aporta a ser recompensado al momento de terminar el régimen. A grandes rasgos, el haber absoluto se compone de todos los bienes que los cónyuges adquieran a título oneroso 
todos cuales serán administrados por el marido durante la vigencia del régimen y deberán ser liquidados al momento de su terminación; la separación de bienes, régimen de corte individualista, que privilegia la autonomía patrimonial de cada uno de los cónyuges, quienes conservan en todo momento la plena y libre administración de sus bienes, al tiempo que omite cualquier mecanismo destinado a producir un reparto de las ganancias que obtengan los cónyuges durante la vigencia del matrimonio; y la participación en los gananciales en su variedad crediticia, régimen introducido en 1993, que durante la vigencia del matrimonio considera a los cónyuges como separados de bienes para efectos de su administración, para luego, al momento de su terminación, corregir el desigual incremento patrimonial que hubieren experimentado durante su matrimonio por vía de establecer la existencia de un crédito en beneficio de uno de los cónyuges en contra del otro.

Entre los señalados regímenes, especial relevancia cobra el de la sociedad conyugal, por dos razones. En primer lugar, porque dado su carácter legal y supletorio, presenta una prevalencia frente a los otros regímenes al momento de celebrarse el matrimonio ${ }^{54}$, sobre todo entre aquellas parejas que no cuentan con un grado de cultura adecuado, que no disponen de acceso a información sobre las características del régimen o a una asesoría letrada, o que no tienen la madurez necesaria para poder discutir las consecuencias patrimoniales de la unión que se está contrayendo ${ }^{55}$, personas que son precisamente quienes conforman el grupo más vulnerable y por tanto más necesitado de una protección adecuada. Sin embargo, no debe olvidarse que existe una segunda razón por la cual la sociedad conyugal es importante en nuestro ordenamiento: dentro de los regímenes matrimoniales, la sociedad conyugal es el llamado a reflejar en

durante la vigencia del régimen, mientras que el relativo está constituido por los bienes de naturaleza mueble que los cónyuges aportan al matrimonio -se encontraban en su patrimonio al momento de contraerlo- $o$ adquieren a título gratuito durante la vigencia del régimen. El patrimonio propio de cada cónyuge, por su parte, contiene, principalmente, los bienes inmuebles de su propiedad al momento de contraer matrimonio y aquellos que adquiere a título gratuito durante la vigencia del régimen (por ejemplo, los inmuebles heredados), sin perjuicio de otros bienes particulares que sean excluidos del patrimonio social por voluntad de los mismos cónyuges. Estos bienes permanecen en el patrimonio de su dueño tanto durante la vigencia del régimen, como al momento de su término". Gatica RodríGuez, María Paz (2011): "El Destino de la Sociedad Conyugal", en: Anuario de Derechos Humanos (Santiago, Centro de Derechos Humanos, Universidad de Chile), p. 170.

${ }^{54}$ Según las cifras entregadas por el Servicio de Registro Civil a noviembre de 2012, un 54,85\% de las parejas casadas quedaron sometidas al régimen de sociedad conyugal, mientras que un $42,8 \%$ optó por el régimen de la separación de bienes y sólo un 2,35\% lo hizo por la participación en las gananciales. SERVICIO de ReGISTRO CIVIL: http://www.registrocivil.cl/PortalOI/Estadisticas_enfoque/estadisticas_enfoque_1.html [visitado el 29/04/2013].

${ }^{55}$ SChmidt Hott, Claudia (1999): "Régimen Patrimonial y Autonomía de la Voluntad", en: Revista Chilena de Derecho. Pontificia Universidad Católica de Chile (Vol. 26, №1), p. 106. 
el ámbito patrimonial la comunidad de vida que se forma entre los cónyuges, debiendo en consecuencia resaltar por su carácter solidario y protector del cónyuge que se encuentra en una posición de debilitad, frente al predominio de la individualidad de cada cónyuge que supone la separación de bienes y a las dificultades prácticas de aplicación que han hecho del régimen de participación en los gananciales un experimento fallido.

Pues bien, la sociedad conyugal desarrolla estos fines de manera poco satisfactoria, pues al hacerlo compromete otros bienes que deben ser tutelados por nuestro ordenamiento, como son la igualdad entre los cónyuges y la protección de la individualidad de cada uno de ellos: en efecto, la actual regulación desarrolla los fines comunitarios antes señalados sacrificando los intereses de uno de los cónyuges (la mujer) quien por el hecho del matrimonio bajo este régimen quedará privada de la administración de sus bienes propios (la cual quedará radicada en su marido ${ }^{56}$ ) y se verá impedida de poder administrar los bienes sociales, aun cuando exista acuerdo de los cónyuges en este sentido, salvo en los casos calificados previstos en los artículos 138 y 1758 del Código civil ${ }^{57}$. Frente a esta situación, el derecho que confieren a la mujer los artículos 150, 166 y 167 del Código civil, en orden a tener un patrimonio reservado, no sujeto a la administración del marido, no puede ser considerado suficiente, sobre todo porque las complejidades propias del régimen generan incertidumbre entre los terceros quienes, al no poder determinar fácilmente a cuál de los diversos patrimonios pertenece el bien que será objeto de un acto o contrato, simplemente tenderán a exigir indistintamente la comparecencia del marido, con el fin de resguardar su valide $z^{58}$. Ciertamente, las reglas expuestas resultan sumamente cuestionables frente a los imperativos constitucionales e internacionales reconocidos por el país, razón por la cual no es de extrañar

\footnotetext{
${ }^{56}$ Conforme a lo dispuesto en los artículos 1749 y 1754 del Código civil. Si bien en las señaladas disposiciones se exige la autorización de la mujer a fin de poder celebrar aquellos actos de mayor significación económica, la regla presenta dos claras anomalías: mientras, por una parte, no es aplicable a la situación inversa, de manera que el hombre que contraiga matrimonio seguirá administrando sin restricciones sus bienes propios; por otra contempla una excepción calificadísima, permitiendo a la mujer administrar sus bienes propios sólo en el caso de ausencia del marido o de negativa injustificada de éste a realizar un determinado acto, debiendo obtener en ambos casos una autorización judicial (arts. 138 y 138 bis CC).

${ }^{57}$ Mientras en la primera de estas disposiciones la posibilidad de ejercer la administración de los bienes sociales por parte de la mujer es conferida frente a la existencia de un impedimento transitorio que impide al marido actuar, caso en el cual la mujer deberá solicitar autorización judicial y acreditar un perjuicio en la demora, en la segunda de ellas se contempla la administración extraordinaria de la sociedad conyugal, la cual quedará entregada a la mujer en aquellos casos en que por larga ausencia o incapacidad del marido ésta hubiese sido nombrada su curadora o curadora de sus bienes.

${ }^{58}$ Gatica Rodríguez, María Paz (2011): "El Destino de la Sociedad Conyugal", en: Anuario de Derechos Humanos (Santiago, Centro de Derechos Humanos, Universidad de Chile), p. 176.
} 
que su conformidad fuera desafiada en el sistema interamericano de derechos humanos, contexto en el cual el Estado de Chile se comprometió el año 2007 en virtud de un Acuerdo de Solución Amistosa ${ }^{59}$ a revisar su normativa interna ${ }^{60}$. Considerando estos antecedentes, no podemos sino concluir que la reforma de la sociedad conyugal es un tema de primera importancia, que debe ser afrontado por el legislador a la brevedad, resultando sumamente criticable la lentitud con que se ha buscado una solución a esta situación.

Las propuestas que han sido sometidas a tramitación ante el Congreso por parte del Ejecutivo ${ }^{61}$ han buscado la creación de un régimen que logre el cumplimiento de tres objetivos, cuales son la igualdad ante la ley de marido y mujer, la plena capacidad jurídica de ambos cónyuges, y la protección económica del cónyuge que se ha dedicado al cuidado de los hijos o del hogar o que ha trabajado en menor medida de lo que hubiese querido o podido por estas causas $^{62}$, pudiendo caracterizarse este régimen como una reforma al actualmente existente $^{63}$, centrándose el elemento igualitario en la libre designación de aquel de los cónyuges que tendrá la calidad de administrador de la sociedad conyugal ${ }^{64}$ y en el hecho que, a falta de designación, la administración sea conjunta, al tiempo que los bienes propios de cada cónyuge son administrados por sus respectivos propietarios ${ }^{65}$.

Sin perjuicio de las buenas intenciones que inspiran el proyecto, éste adolece de serias falencias. Por lo pronto, la necesidad de que exista un administrador de la sociedad parece ser una medida que pugna con el respeto de la individualidad

${ }^{59}$ Acuerdo de Solución Amistosa. Caso № 12.433. Sonia Arce Esparza con Chile.

${ }^{60}$ Gatica Rodríguez, María Paz (2011): "El Destino de la Sociedad Conyugal", en: Anuario de Derechos Humanos (Santiago, Centro de Derechos Humanos, Universidad de Chile), p. 171.

${ }^{61}$ Boletín № 7567-07 y 7718-18. Para un análisis de las reformas en curso, Gatıca Rodrícuez, María Paz (2011): "Análisis Comparativo de los Nuevos Proyectos de Ley que Reforman el Régimen de Sociedad Conyugal. Boletines Nos. 7567-07 y 7718-18", en: Revista de Derecho Escuela de Postgrado, Universidad de Chile, pp. 225-241; Barcia Lehmann, Rodrigo (2012): "Derecho de Familia. Desafíos Año 2013", en: La Semana Jurídica (Año 1, № 27), semana del 24 al 28 de diciembre de 2012, pp. 6-7.

${ }^{62}$ Gatica Rodríguez, María Paz (2011): "Análisis Comparativo de los Nuevos Proyectos de Ley que Reforman el Régimen de Sociedad Conyugal. Boletines Nº. 7567-07 y 7718-18", en: Revista de Derecho Escuela de Postgrado, Universidad de Chile, pp. 227-228.

${ }^{63}$ En lugar de la creación de un nuevo régimen legal y supletorio en reemplazo de la sociedad conyugal, como en alguna oportunidad se planteó, podría ser una comunidad diferida con administración conjunta entre los cónyuges.

${ }^{64}$ Administración que se encuentra sujeta a limitaciones en lo que se refiere a bienes de importancia económica, que la tornan en la práctica una administración conjunta.

${ }^{65}$ Otras reformas son la modificación de las reglas que determinan la formación del haber social y del haber propio de cada cónyuge, así como la eliminación del haber relativo, todo esto con la finalidad de simplificar su funcionamiento. 
de cada uno de los cónyuges, circunstancia que, atendido el bien jurídico que se ve comprometido, no puede ser salvada por la mera referencia a la existencia de un acuerdo en orden a cuál de ellos desarrollará esta función. Frente a esta circunstancia, resulta aconsejable su revisión y reemplazo por un sistema de administración conjunta o indistinta, conservando en el segundo caso las reglas de autorizaciones destinadas a proteger los bienes de mayor significación económica. Sin embargo, lo que parece más problemático en el proyecto es la subsistencia del patrimonio reservado: con la finalidad de proteger a la mujer, el actual proyecto lo contempla única y exclusivamente para aquellos casos en que el marido sea el administrador de la sociedad, con lo cual es esperable que en la práctica se mantenga en esencia el mismo régimen vigente hasta el momento. Como contrapartida, en aquellos casos en que esta posición la ocupe la mujer, el marido no contará con ningún mecanismo que le permita administrar los bienes que adquiera durante el matrimonio, generándose una nueva suerte de incapacidad, esta vez en perjuicio del hombre ${ }^{66}$. Finalmente, nos parece que el proyecto yerra al pretender solucionar los problemas de administración por vía de mantener instituciones cuestionables frente a las exigencias que impone el reconocimiento de una solidaridad familiar y una efectiva comunidad de destinos entre los cónyuges, lo cual queda bien reflejado en la subsistencia de la figura de la renuncia a los gananciales que puede hacer el cónyuge no administrador.

\section{Cuidado personal: la corresponsabilidad parental}

En el Derecho chileno las relaciones entre padres e hijos tienen dos esferas de regulación, diferenciándose por un lado el aspecto personal (que corresponde al cuidado personal) y por otro el patrimonial (la patria potestad ${ }^{67}$ ), de manera que se mantiene hasta el día de hoy una división que no se justifica y que ha sabido resistir las diversas reformas en materia de familia como un resabio legislativo, hecho que ha sido criticado por la mayoría de la doctrina ${ }^{68}$. En este sentido, se ha señalado por el profesor Álvarez que "la separación que se mantiene en nuestra ley entre autoridad paterna y patria potestad, reguladas en títulos distintos y como instituciones diversas, carece hoy de justificación.

\footnotetext{
${ }^{66}$ Barcia Lehmann, Rodrigo (2012): “Derecho de Familia. Desafíos Año 2013”, en: La Semana Jurídica (Año 1, № 27), semana del 24 al 28 de diciembre de 2012, p. 7.

${ }^{67}$ Mientras que el cuidado personal se regula en el Título IX del Libro I del Código civil, entre los artículos 222 y 242, la patria potestad se encuentra tratada en el Título X del mismo libro, entre los artículos 243 y 273.

${ }^{68}$ A modo de ejemplo, la profesora Lathrop llega a afirmar que "Chile prácticamente es el único país que conserva la división anacrónica entre patria potestad y cuidado personal". LATHROP GómEz, Fabiola (2013): Cuidado Personal y Relación Directa y Regular. Estudio Exploratorio en los Tribunales de Familia de la Región Metropolitana (Santiago, Editorial Abeledo-Perrot), p. 86.
} 
En efecto, la división actual no se funda en una cuestión de contenidos ya que éstos se entrecruzan en forma permanente, sino que tal escisión arranca del hecho de que el padre o madre legítima tiene respecto de su hijo tanto autoridad paterna como patria potestad, mientras que el padre o madre natural sólo tiene la primera, careciendo de la segunda"69.

Como puede apreciarse, esta división carece en la práctica de sentido, puesto que supone la posibilidad de división del ejercicio de los derechos concernientes a la relación paterno-filial entre los progenitores. Es sobre la base de esta división que nuestra doctrina se ha encargado de definir la autoridad paterna con exclusión de la patria potestad, señalando que se trata del conjunto de derechos funciones de carácter personal, reservando el concepto de patria potestad para los que revisten connotación patrimonial ${ }^{70}$, cuestión que a raíz de su indeterminación puede resultar problemática al momento de analizar el cuidado personal, puesto que el artículo 224 CC, tal como señala la profesora SCHMIDT, alude a un deber de carácter genérico, que comprende en términos generales a todos aquellos que corresponden a los padres frente a los hijos ${ }^{71}$.

En Chile el sistema del cuidado personal se regula en el Título IX del Libro I del Código civil ${ }^{72}$, entre los artículos 222 y 242, disposiciones que se ven complementadas por la Ley $\mathrm{N}^{\circ} 16.618$ (ley de menores) y la antes mencionada Ley $\mathrm{N}^{\circ} 19.947$, que hace mención al cuidado personal cuando regula el contenido mínimo que debe tener el acuerdo regulador en los casos de nulidad, separación y divorcio ${ }^{73}{ }^{74}$. En cuanto al concepto de cuidado personal, se ha dicho por la doctrina que éste no se puede delimitar claramente, pudiendo a lo más decirse que se relaciona con la idea de qué progenitor convive con los hijos, sin determinar mayoritariamente los derechos, deberes y limitaciones que ello conlleva ${ }^{75}$.

69 Álvarez CID, Carlos (1998): “Derechos y Obligaciones entre Padres e Hijos, en Particular de la Autoridad Paterna", en: Revista de Derecho, Universidad de Concepción (№ 204, Año LXVI), p. 63.

${ }^{70}$ LAthrop Gómez, Fabiola (2011): "La Corresponsabilidad Parental", en: VV.AA., Estudios de Derecho Civil (Santiago, Editorial Abeledo-Perrot), tomo V, p. 558.

71 Schmidt Hott, Claudia y Veloso Valenzuela, Paulina (2001): La Filiación en el Nuevo Derecho de Familia (Santiago, Lexis-Nexis), p. 253.

72 Cuyo título "De los derechos y obligaciones entre los padres y los hijos" nos indica el carácter general de sus regulaciones, referidos a todos los aspectos personales de la relación paterno-filial.

73 Artículos 21, 27 y 55 de la Ley $N^{\circ} 19.947$.

${ }^{74}$ Por su parte, en la Ley $N^{0} 19.968$ (ley de tribunales de familia) se contempla que las cuestiones relativas al cuidado personal de las niñas, niños y adolescentes se tramitarán en conformidad al procedimiento ordinario, párrafo cuarto del Título III, artículos 55 y siguientes.

${ }^{75}$ Lathrop Gómez, Fabiola (2013): Cuidado Personal y Relación Directa y Regular. Estudio Exploratorio en los Tribunales de Familia de la Región Metropolitana (Santiago, Editorial Abeledo-Perrot), p. 90. 
Sin embargo, esta situación se ha visto alterada por la Ley $N^{\circ} 20.680$, normativa que poniendo énfasis en el interés superior de los niños ${ }^{76}$, incorpora en nuestro Derecho el concepto de "corresponsabilidad parental", en virtud del cual "ambos padres, vivan juntos o separados, participarán en forma activa, equitativa y permanente en la crianza y educación de los hijos" (art. 224 inc. $1^{\circ} \mathrm{CC}$ ), en términos tales que parece restringir el antiguo concepto de cuidado personal a un elemento más bien de carácter material, referido a quien vivirá de manera regular con el niño y lo tendrá bajo su cuidado directo. En efecto, frente a este concepto de cuidado personal, la corresponsabilidad aparece como un término amplio, que exige un involucramiento directo y continuo de ambos padres en la crianza del hijo, el cual abarca desde el derecho-deber que tiene cada padre de definir cómo será criado su hijo y qué valores serán transmitidos en un ambiente de cariño y que al mismo tiempo incentive su desarrollo intelectual, hasta la toma de decisiones sobre su enseñanza, comprendiendo tanto aspectos académicos como los sociales, incluyendo el saber compartir, el ser sociable, respetuoso, honesto y tolerante ${ }^{77}$. Estos derechos y deberes propios de la relación paterno-filial son tan fuertes, que no es de extrañar que autores modernos pongan énfasis en su carácter indisoluble ${ }^{78}$.

Ciertamente, la afirmación de este principio de corresponsabilidad parental presenta importantes ventajas, partiendo por el hecho que obliga a ambos progenitores a involucrarse de manera activa en la crianza del niño, haciéndolos también responsables de tomar las decisiones que le conciernan, pensando siempre en su mayor beneficio; a lo cual se suma el hecho que su propio ejercicio fomenta los vínculos paterno-filiales en virtud del contacto permanente, lo cual disminuye el impacto psicológico que sufre el hijo o hija como consecuencia de la ruptura de la relación de sus progenitores. Finalmente, desde la perspectiva de los padres, se puede afirmar que la corresponsabilidad contribuiría no

\footnotetext{
${ }^{76}$ Hecho que queda bien reflejado en una modificación de profundo carácter simbólico, como fue el alterar el orden de los dos incisos del artículo 222 CC, de manera tal que en la actualidad el Título en análisis parte por una afirmación solemne en orden a que "La preocupación fundamental de los padres es el interés superior del hijo, para lo cual procurarán su mayor realización espiritual y material posible, y lo guiarán en el ejercicio de los derechos esenciales que emanan de la naturaleza humana de modo conforme con la evolución de sus facultades".

77 Sin embargo, como una consecuencia de la separación entre los aspectos personales y los patrimoniales, no importará necesariamente una responsabilidad compartida por las decisiones referidas al ámbito patrimonial, las cuales serán tomadas por aquel de los padres que detente la patria potestad.

${ }^{78}$ PARKINSON, Patrick, "Family Law and the Indissolubility of Parenthood", en: Family Law Quarterly (No 40), pp. 237-280. Citado en: Rodríguez Pinto, María Sara (2009): "El Cuidado Personal de Niños y Adolescentes en la Familia Separada: Criterios de Resolución de Conflictos de Intereses entre Padres e Hijos en el Nuevo Derecho Chileno de Familia", en: Revista Chilena de Derecho, Pontificia Universidad Católica de Chile (Vol. 36, № 3), p. 546.
} 
sólo a hacer efectivo el principio de la igualdad ante la ley, al desarrollar una efectiva igualdad parental, sino que también permitiría crear una sociedad más igualitaria, al cambiar el paradigma ancestral bajo el cual se piensa que, una vez producida la separación, los hijos e hijas deben ser criados por la madre, limitándose el padre a desempeñar un rol de proveedor a través del pago de las obligaciones alimenticias.

Ahora bien, en lo concierne propiamente al cuidado personal, la nueva Ley $N^{\circ} 20.680$ no altera la regulación vigente hasta junio de 2013 en lo relativo a la existencia de los tres mecanismos de atribución, distinguiéndose todavía entre una vía convencional ${ }^{79}$, legal y judicial. Por el contrario, como analizaremos a continuación, lo que sí sufrió una profunda reforma son los elementos considerados por la regla de atribución legal y los criterios conforme a los cuales el juez debe resolver una contienda que verse sobre la atribución del cuidado personal.

La primera de las reformas señaladas afectó a la regla de atribución legal del cuidado personal, que hasta junio de este año disponía que, en caso que los padres vivan separados, el cuidado personal corresponderá a la madre (art. 225 inc. $1^{\circ} \mathrm{CC}$ ), siendo reemplazada por el nuevo inciso $3^{\circ}$ del artículo $225 \mathrm{CC}$, conforme con el cual "A falta del acuerdo del inciso primero, los hijos continuarán bajo el cuidado personal del padre o madre con quien estén conviviendo". Para poder comprender el sentido de esta modificación, es necesario exponer los motivos sostenidos por los adherentes de la regla de atribución preferente en beneficio de la madre y los argumentos desarrollados por quienes la rechazan.

En apoyo de la regla vigente hasta junio de 2013, se ha dicho que ésta no haría sino constatar un hecho natural, como es el apego existente entre aquel de los progenitores que engendra y el hijo, destacándose en este sentido que, mientras la paternidad puede ser social o incluso inexistente, la maternidad es un vínculo natural y necesario. Como correlato de esta situación, ahora desde la perspectiva social, la realidad chilena demuestra que al ocurrir un quiebre

\footnotetext{
${ }^{79}$ Debe destacarse esta posibilidad, por cuanto da cuenta de un reconocimiento de la autonomía de la voluntad de los padres para regular las relaciones parentales. En la práctica, será especialmente importante cuando se haga por vía del acuerdo completo y suficiente, al que hemos hecho referencia, ocasión en que los padres podrán alterar la atribución legal a favor de la madre o bien establecer un régimen de coparentalidad. Lathrop Gómez, Fabiola (2005): Cuidado Personal de los Hijos: Análisis de la Ley de Matrimonio Civil y Tribunales de Familia (Santiago, Editorial Puntolex), p. 17; Lathrop Gómez, Fabiola (2010): "Custodia Compartida, Acuerdo de los Padres y Establecimiento de Oficio: Un Fallo en Ausencia de Ley", en: Revista de Derecho, Universidad Austral, Valdivia (Vol. XXIII, № 2), pp. 237-245. Sin embargo, es un mecanismo no exento de críticas: por una parte, la madre puede verse forzada económicamente a prestar su consentimiento, mientras que por otra puede no respetarse adecuadamente el derecho del niño a ser oído, puesto que no menciona que en dicho convenio que su opinión o deseo debe ser considerado, siendo que se trata de una cuestión que le atañe directamente.
} 
en la relación de pareja, se encuentre ésta basada en el matrimonio o en una unión de hecho, es la madre quien asume el cuidado de manera inmediata, al permanecer junto a sus hijos. Esta situación se ve extremada en el caso de las familias monoparentales, donde habitualmente la única figura presente será la madre. Acorde con lo expuesto, al reconocer la ley chilena este hecho estaría evitando la judicialización de los conflictos, puesto que determina una atribución que se produce de manera inmediata, sin que exista una "zona gris" o un vacío al momento del quiebre, en la espera que los padres resuelvan sus conflictos personales.

Por otro lado, quienes criticaban esta solución esgrimían que era inconstitucional, debido a que contiene un elemento discriminatorio, porque, por un lado, se encasilla a la mujer en un rol de cuidadora, relacionado con una visión tradicional que la pone al cuidado de los hijos; al tiempo que afectaba los intereses del padre, quien se ve privado de la posibilidad de ejercer el cuidado personal por cuestiones ajenas a sus capacidades e idoneidad. Dentro de la doctrina chilena, una de las exponentes más claras de esta tendencia fue la profesora LATHROP, quien abogaba por la inconstitucionalidad del artículo 225 inc. $1^{\circ 80} \mathrm{CC}$, bajo los siguientes argumentos: a) su falta de idoneidad, por cuanto no satisface al interés superior del niño como interés constitucional preferente; destacándose además el hecho que tampoco es consecuente con su rol de regla supletoria, por cuanto esas reglas reproducen el supuesto arreglo a que habrían Ilegado los padres antes del conflicto; b) su falta de proporcionalidad, por cuanto existen otros medios idóneos para evitar que las partes lleguen a los tribunales, sin que sea necesario sacrificar el principio de la igualdad de los padres; c) finalmente, porque sacrifica la igualdad del padre, sin cumplir con el test de razonabilidad, ni de proporcionalidad, infringiéndose por esta razón el artículo $19 \mathrm{~N}^{\circ} 2 \mathrm{CPol}$ y los tratados sobre igualdad de género suscritos por Chile $^{81}$. Como consecuencia de lo expuesto, la regla no sólo afectaría al padre, sino también a la madre, dado que se estaría alterando la igualdad material de la mujer al estereotiparse los roles de la familia, toda vez que el diseño responde a un modelo donde el padre es el proveedor y la madre la que se queda al cuidado de los hijos ${ }^{82}$.

\footnotetext{
80 Lathrop Gómez, Fabiola (2010): “(In)constitucionalidad de la Regla de Atribución Preferente Materna del Cuidado Personal de los Hijos del Artículo 225 del Código Civil Chileno", en: Ius et Praxis, Universidad de Talca (Año 16, № 2), pp. 147-184.

${ }^{81}$ Particularmente, la Convención sobre la Eliminación de Todas las Formas de Discriminación contra la Mujer.

${ }^{82}$ Barcia Lehmann, Rodrigo (2011): Fundamentos del Derecho de Familia y de la Infancia (Santiago, Puntolex), p. 484.
} 
Con la finalidad de propiciar una revisión de estas reglas, con fecha 29 de junio de 2010 ingresó a la Cámara de Diputados el Boletín №7007-18, que sería posteriormente refundido con el Boletín № 5917-18, antecedente de la Ley $\mathrm{N}^{\circ} 20.680$. En lo que concierne a la regla de atribución legal, el proyecto fue objeto de modificaciones, defendidas y criticadas desde la doctrina, pasando desde la conservación de la regla legal con el carácter de atribución provisoria del cuidado personal a la madre (basada en el deseo de la Cámara de Diputados de evitar la judicialización de los conflictos familiares), hasta arribar a la regla adoptada por el Senado, que confería provisoriamente el cuidado personal a la persona con quien resida el niño o niña, se trate de uno de sus padres o de un tercero ${ }^{83}$, sujeto a un control judicial.

La disparidad de criterios entre ambas Cámaras obligó a la formación de una Comisión Mixta, la cual resolvió, siguiendo el criterio del Senado, atribuir el cuidado personal a aquel de los padres con quien el niño esté conviviendo, en una solución que no ha estado exenta de críticas, las cuales miran a lo desacertado de utilizar una expresión propia del ámbito de la regulación de las uniones de pareja; a que se trataría de una regla que exacerba el conflicto familiar, pues crearía un incentivo para expulsar al otro padre del hogar común a fin de conservar el cuidado personal de los hijos; a que crearía situaciones de inseguridad jurídica para el niño, dada la imposibilidad en que se encuentran los terceros de poder saber a ciencia cierta con quién éste convive; y a que, dada la realidad social chilena, de manera encubierta y bajo un lenguaje neutro desde la perspectiva de género se estaría manteniendo el privilegio materno.

Por otro lado, la segunda de las reformas introducidas por la Ley $N^{\circ} 20.680$ mira a los criterios que permiten definir la atribución judicial del cuidado personal. Conforme a la legislación anterior, y dada la regla de preferencia materna, la atribución judicial operaba sobre todo en aquellos casos en que el padre quisiera revertir la atribución legal, por existir motivos que hagan inhábil a la madre para ejercer el cuidado personal, conforme a lo dispuesto en el entonces inciso $3^{\circ}$ del artículo 225 del Código civil, en relación con el artículo 42 de la Ley № $16.618^{84}$.

\footnotetext{
${ }^{83}$ Para una visión crítica de las reformas introducidas por el Senado, consúltese CoRRAL TALCIANI, Hernán (2013): "Proyecto de Ley Sobre Tuición: ¿Legislando a la Chilena? Disponible en: http://corraltalciani.wordpress.com/2013/03/17/proyecto-de-ley-sobre-tuicion-legislando-a-la-chilena/ [visitado el 29/04/2013]; Arancibia Obrador, María José (2012): "Deficiencias en el Proyecto de Reforma sobre Cuidado Personal", en: El Mercurio Legal, 12 de abril de 2012. Disponible en: http://www.elmercurio. com/Legal/Noticias/Opinion/2013/04/12/Deficiencias-del-proyecto-de-reforma-sobre-cuidado-personal. aspx [visitado el 29/04/2013].

${ }^{84} \mathrm{Si}$ bien ambas disposiciones se basaban en el principio normativo del interés superior del niño, su interpretación resultaba compleja, toda vez que los casos señalados en ellas parecían sugerir que sólo procede en aquellas circunstancias en que la madre estaba afectada de una inhabilidad física o moral que le impide cuidar a su hijo.
} 
Nuestro legislador, dejando de lado esta regla por considerarla discriminatoria y contraria al interés superior del niño, derogó la preferencia con que contaba la madre, poniendo a ambos padres en un pie de igualdad al momento de discutirse judicialmente la atribución del cuidado personal (art. 225 inc. $4^{\circ} \mathrm{CC}$ ), debiendo el juez fundar su decisión en el interés superior del niño, considerando los criterios establecidos en el artículo 225-2 CC ${ }^{85}$ y sin poder resolver únicamente considerando la capacidad económica de los padres (art. 225 inc. $5^{\circ} \mathrm{CC}$ ).

Finalmente, en la línea de propender a una efectiva corresponsabilidad parental y de flexibilizar el rigor que supone la existencia de una regla de atribución legal a favor de uno de los padres, nuestro legislador reconoció la figura del cuidado personal compartido, caracterizándolo en el artículo 225 inc. $2^{\circ}$ como "un régimen de vida que procura estimular la corresponsabilidad de ambos padres que viven separados, en la crianza y educación de los hijos comunes, mediante un sistema de residencia que asegure su adecuada estabilidad y continuidad". Hasta la entrada en vigencia de la Ley $N^{\circ} 20.680$, si bien la figura gozaba en el país de reconocimiento doctrinal y cierto respaldo jurisprudencial ${ }^{86}$, no resultaba del todo indubitada su procedencia ${ }^{87}$, razón por la cual consideramos que la importancia de la reforma radica precisamente en el expreso reconocimiento de la figura y en el valor simbólico que tiene su afirmación legislativa, como un modelo de parentalidad integrador después de la ruptura. Sin embargo, su aplicación en la práctica estará condicionada a la efectiva existencia de un acuerdo entre los padres, procediendo en consecuencia solamente como una forma de atribución convencional del cuidado personal

${ }^{85}$ Entre los cuales destacan: a) la vinculación afectiva entre el hijo y sus padres, y demás personas de su entorno familiar; b) la aptitud de los padres para garantizar el bienestar del hijo y la posibilidad de procurarle un entorno adecuado, según su edad; c) la contribución a la mantención del hijo mientras estuvo bajo el cuidado personal del otro padre, pudiendo hacerlo; d) la actitud de cada uno de los padres para cooperar con el otro, a fin de asegurar la máxima estabilidad al hijo y garantizar la relación directa y regular, para lo cual considerará especialmente lo dispuesto en el inciso quinto del artículo 229; e) la dedicación efectiva que cada uno de los padres procuraba al hijo antes de la separación y, especialmente, la que pueda seguir desarrollando de acuerdo con sus posibilidades; f) la opinión expresada por el hijo; g) el resultado de los informes periciales que se haya ordenado practicar; h) Los acuerdos de los padres antes y durante el respectivo juicio; i) el domicilio de los padres; j) cualquier otro antecedente que sea relevante atendido el interés superior del hijo.

${ }^{86}$ Sobre todo si se considera que, en la actualidad, existe una mayoritaria tendencia a considerar válido un acuerdo de cuidado personal compartido, ver nota 79 .

${ }^{87}$ En este sentido, en su sentencia de fecha 6 de agosto de 2012, la Corte Suprema invocando tanto la falta de una normativa legal que lo respalde, como la ausencia de aquellas condiciones mínimas que posibiliten su aplicación en la práctica, resolvió dejar sin efecto un régimen de cuidado personal compartido. Corte Suprema, sentencia de 6 de agosto de 2012, Rol № 2022-2012, Legalpublishing CL/ JUR/1629/2012;62326. Con todo, a un resultado similar por una vía indirecta se puede llegar conforme a las reglas entonces vigentes por medio de establecer una relación directa y regular amplia. 
(art. 225 inc. $1^{\circ} \mathrm{CC}$ ), encontrándose imposibilitado el juez de imponer este régimen como una modalidad de cuidado personal definido por una sentencia.

Sin perjuicio de las ventajas que son atribuidas a este régimen, expresadas en el hecho que favorecen la continuidad de los vínculos familiares, y que hacen de la ruptura de la relación de pareja entre sus padres un evento menos traumático para los niños, debemos destacar el hecho que se trata de una institución no exenta de críticas, las cuales han considerado, por ejemplo, la situación de inestabilidad en que queda el niño (el Ilamado "síndrome de niño mochila" ${ }^{\prime 8}$ ), con su consecuente agotamiento provocado por la falta de pertenencia o raíces a un lugar ${ }^{89}$; así como el hecho que su implementación, sin contar con la anuencia de los padres, aumentaría los juicios motivados por los desacuerdos en la toma de decisiones relativas a los hijos ${ }^{90}$. Por esta razón, resulta elogiable la prudencia con que actuó el legislador nacional, quien supeditó su aplicación a la existencia de un acuerdo entre los padres, excluyéndose la posibilidad de que sea decretada por el juez.

Por su parte, en lo que concierne a la esfera patrimonial de la relación paterno-filial, expresada en la patria potestad, la Ley № 20.680 introdujo también importantes modificaciones destinadas a reforzar la igualdad entre los padres: de esta forma, en el caso que los padres vivan juntos, se reemplazó la regla que

${ }^{88}$ Lathrop Gómez, Fabiola (2013): Cuidado Personal y Relación Directa y Regular. Estudio Exploratorio
en los Tribunales de Familia de la Región Metropolitana (Santiago, Editorial Abeledo-Perrot), p. 104.

89 Tal como cita Rodríguez PINTO, en el estado de California, un viernes por la tarde una madre oye de labios del pequeño amigo de su hija la siguiente frase: "Bye Eve, I don't remember who I belong to tonight". MANSON, Mary Ann (1999): The Custody Wars (New York, Basic Books), p. 1. Citado en: Rodríguez PINTO, María Sara (2011): "La Tuición Compartida o Alternada en Chile. Conflictos entre el Interés Superior del Niño y los Intereses de Padres Separados", en: VV.AA., Estudios de Derecho Civil, (Santiago, Editorial Abeledo-Perrot), tomo V, p. 572.

${ }^{90}$ Por esta razón, no resulta extraño que se hayan señalado una serie de condiciones para que el régimen resulte exitoso, entre las cuales se encuentran: a) acuerdo de ambos progenitores, ya sea por medio de una transacción o de una conciliación; b) existencia de un entorno físico adecuado que permita que el niño cuente con las mismas comodidades en ambos hogares; c) que las partes hayan superado el conflicto que las llevó a la ruptura conyugal, de forma tal que su relación se desarrolle en el ámbito del entendimiento y respeto; d) que el padre haya cumplido con las obligaciones que emanan de la filiación, tales como el derecho de alimentos y la relación directa y regular; e) que los hogares de los padres no se encuentren a una distancia excesiva que interfiera con las rutinas generales del niño, por ejemplo el traslado diario al colegio; f) que exista unidad de criterio en materias de educación y crianza del niño, niña o adolescente por parte de ambos progenitores; h) que exista un cambio de mentalidad de la sociedad, en donde se entienda que el niño tiene derecho a ser criado por ambos padres y que dicha labor no sólo la puede ejercer la madre; i) que ambos padres sean hábiles para ejercer el cuidado personal; j) y el nivel socioeconómico de los padres no es un antecedente relevante esto quiere decir que no queda supeditado a este facto la determinación y debe ser interpretado a favor de las partes y nunca en contra de ellas. Lathrop Gómez, Fabiola (2013): Cuidado Personal y Relación Directa y Regular. Estudio Exploratorio en los Tribunales de Familia de la Región Metropolitana (Santiago, Editorial Abeledo-Perrot), p. 121. 
confería a falta de acuerdo la patria potestad al padre (antiguo art. 244 inc. $2^{\circ}$ $\mathrm{CC}$, por un sistema de ejercicio conjunto para todos los actos que no sean de mera conservación, quedando estos últimos sometidos a un ejercicio indistinto (art. 244 inc. $2^{\circ}$ y $3^{\circ} \mathrm{CC}$ ). En caso de desacuerdo entre los padres, o cuando uno de ellos esté ausente, o impedido, o se negare injustificadamente a prestar su consentimiento para la realización de este acto, se requerirá autorización judicial (art. 244 inc. $3^{\circ} \mathrm{CC}$ ).

En aquellos casos en que los padres viven separados, la patria potestad solamente podrá ser ejercida de manera conjunta cuando se haya acordado un régimen de cuidado personal compartido (art. 245 inc. $1^{\circ} \mathrm{CC}$ ): en todos los restantes casos, corresponderá su ejercicio a aquel de los padres que tenga el cuidado personal del niño, a menos que medie una resolución judicial que la confiera al otro o que establezca un ejercicio conjunto (art. 245 inc. $2^{\circ} \mathrm{CC}$ ). Como puede apreciarse, la aplicación de esta regla no provocará mayores inconvenientes en el caso que el cuidado personal sea atribuido por medio de un acuerdo o de una resolución judicial, dado que en ambos casos deberá ser subinscrito al margen de la inscripción de nacimiento del niño. Por el contrario, cuando sea la ley quien atribuya el cuidado personal (art. 225 inc. $3^{\circ} \mathrm{CC}$ ) se reproducirán los mismos problemas que existían bajo la legislación anterior $^{91}$, habida consideración que los terceros no tienen por qué saber si los padres viven o no separados, ni mucho menos con cuál de ellos efectivamente convive el niño, lo cual llevará indudablemente en la práctica a que se solicite la autorización de ambos padres para la realización de aquellos actos que, no siendo de mera conservación, afecten el patrimonio del hijo.

\section{Desafíos futuros del Derecho de familia en Chile}

Una vez analizados cuáles son los principales desafíos que enfrenta actualmente el Derecho de familia en Chile, nos interesa exponer sobre dos cuestiones que, si bien han sido de objeto de debate a nivel ciudadano, todavía no se han reflejado en iniciativas legales concretas: nos estamos refiriendo al reconocimiento y protección de las familias ensambladas y al matrimonio igualitario, temas que ocuparán las últimas páginas de este artículo.

Reconocimiento y protección de las familias ensambladas

Como señalamos al inicio de este trabajo, una de las reformas más importantes que ha experimentado el Derecho de familia chileno fue la introducida por la Ley $\mathrm{N}^{\circ} 19.585$, que inspirada en la plena vigencia del principio de igualdad, eliminó las diferencias hasta ese momento existentes en cuanto a las

${ }^{91}$ Ramos Pazos, René (2007): Derecho de Familia, Sexta Edición Actualizada (Santiago, Editorial Jurídica de Chile), tomo II, p. 457. 
categorías de filiación y supuso un importante avance en el reconocimiento y protección de todas las familias ante la ley. Sin embargo, más allá de este importante avance, su aprobación tuvo un paradójico efecto en lo que concierne a las familias ensambladas, expresado particularmente en el reformado artículo 228 CC, disposición conforme a la cual "La persona casada a quien corresponda el cuidado personal de un hijo que no ha nacido de ese matrimonio, sólo podrá tenerlo en el hogar, con el consentimiento de su cónyuge" $e^{\prime 92-93}$. Como bien puede apreciarse, se trata de una regla que, con el objeto de privilegiar el matrimonio, confiere un derecho absoluto al marido o a la mujer, que le permite repeler al hijo de su cónyuge del hogar común, solución legislativa que implica un menosprecio por la relación paterno-filial generada al alero de una realidad familiar anterior (matrimonial, de convivencia o uniparental), que afecta severamente tanto el interés superior del niño, como el derecho de éste a desarrollar una vida familiar con sus padres, reconocidos en los artículos 3 y 9.1 de la Convención sobre los Derechos del Niño.

Ciertamente, si bien resultaba esperable que la señalada regulación no fuera aplicable ${ }^{94}$, atendido el hecho que muy probablemente el ejercicio de ese derecho por parte de uno de los cónyuges desencadene una crisis en la relación de pareja ${ }^{95}$, no dejaba de resultar simbólica su permanencia en la legislación chilena, que parecía todavía concebir la compleja red de roles y círculos que

\footnotetext{
${ }^{92}$ Esta disposición se encontraba enunciada originalmente en el artículo 278 CC, cuyo inciso segundo decía "Pero la persona casada no podrá tener a un hijo natural en su casa sin el consentimiento de su mujer o marido", en lo que constituía una forma de proteger la familia matrimonial y de evitar discordias entre los cónyuges, según la mentalidad de la época. Sin embargo, durante la tramitación de la Ley № 19.585, un grupo de senadores, obviando los imperativos derivados del interés superior del niño, en lugar de derogar esta disposición, decidieron extender la regla y hacerla aplicable a cualquier hijo que no haya nacido de ese matrimonio. Doyharçabal CASSE, Solange (2002): "Autorización que Debe Prestar el Cónyuge para que el Hijo de su Mujer o Marido Viva en el Hogar Común", en: Temas de Derecho, Universidad Gabriela Mistral (Año XVII, № 1-2), pp. 67-79.

${ }^{93}$ Una segunda expresión de este desconocimiento se produjo a propósito de la derogación del parentesco por afinidad ilegítima, vínculo que existía entre una de dos personas que no han contraído matrimonio y se han conocido carnalmente, y los consanguíneos legítimos o ilegítimos de la otra, según el hoy derogado artículo 32 del Código civil. Como consecuencia práctica de esta derogación, en Chile hoy sería válido el matrimonio que se celebre entre quien fuera conviviente y la hija de su pareja, aun cuando el primero haya desarrollado socialmente una función paterna, situación que implica un desconocimiento del núcleo familiar recompuesto formado en torno a la convivencia.

${ }^{94}$ Siendo un hecho revelador de esta circunstancia el que no hayamos podido encontrar jurisprudencia referida a esta disposición.

${ }^{95}$ En este punto, debemos recordar que en gran medida la familia se presenta como un espacio de "no-derecho", donde sus integrantes van enfrentando y resolviendo los conflictos que en su seno se produzcan, conforme a sus propias dinámicas familiares, siendo excepcional la intervención del aparato estatal, que queda reservada solamente para aquellos casos en que la crisis compromete la subsistencia misma de la familia o de alguno de sus vínculos.
} 
subyacen a la familia ensamblada, estructurada bajo la lógica de la sustitución o de la complementariedad de funciones ${ }^{96}$, como un imposible. Afortunadamente, esta situación fue reformada: una de las novedades de la Ley $N^{\circ} 20.680$ fue la derogación de esta disposición.

Se trata de un importante y significativo primer paso en orden a reconocer a la familia ensamblada como una realidad actualmente existente en la sociedad chilena ${ }^{97}$, que presenta sus propias características y demanda la existencia de reglas de protección acordes a ellas ${ }^{98}$. Sin embargo, es todavía deseable en el futuro un mayor desarrollo legislativo, que incorpore reglas destinadas a proteger el interés del niño ante las situaciones de crisis que esta familia pueda afron$\operatorname{tar}^{99}$, permitiéndole por ejemplo mantener una relación directa y regular con su padre o madre afín y eventualmente poder demandar alimentos, si la ruptura implica un detrimento en su calidad de vida ${ }^{100}$. Sin embargo, en la actualidad no se percibe un genuino interés por legislar sobre la paternidad social, y su

${ }^{96}$ Grosman, Cecilia P.; Martínez Alcorta, Irene (2000): Familias Ensambladas. Nuevas Uniones Después del Divorcio (Buenos Aires, Editorial Universidad), pp. 56-59.

${ }^{97}$ Realidad que, por lo demás, se va haciendo cada día más patente, sobre todo si consideramos que la legislación chilena admite actualmente el divorcio vincular, cuya aplicación dejará abierta la vía para que los antiguos cónyuges formen nuevos proyectos familiares, que demandan reconocimiento por parte de la legislación, sea como matrimonio, sea como convivencia, y que en la actualidad cerca de dos tercios de los nacimientos se producen fuera del matrimonio. Sobre estos últimos datos, SERVICIO DE ReGISTRO CIVIL: http://www.registrocivil.cl/PortalOI/Estadisticas_enfoque/estadisticas_enfoque_1.html [visitado el 29/04/2013].

${ }_{98}$ Sobre este punto, hacemos nuestras las palabras del profesor FuLCHIRON, en orden a que construir relaciones en las familias separadas sobre un modelo unitario no conduce de ninguna forma a negar la pluralidad de situaciones. El legislador pretende simplemente afirmar que si los modos de vida en familia son diversos y en muchos aspectos en continua recomposición, existe al menos un elemento estable en la familia: el vínculo que une al niño a su padre y su madre. FulCHIRON, Hugues (2010): "Pluralisme et Rupture Familiale", en: Odile Roy (dir.), Réflexions sur le Pluralisme Familial (Paris, Presses Universitaires de Paris Ouest), p. 189.

${ }^{99}$ Como señala MOMBerg: "Cuando los niños viven con su padre o madre, que además ejercen el cuidado personal respecto de ellos, el cónyuge de ese padre o madre construye vínculos o lazos fuertes que claramente deben ser reconocidos y por qué no decirlo también legislados y amparados por el derecho, en atención a resguardar el interés superior del niño. Lo mismo podría acontecer respecto de las familias que se forman sobre la base de una convivencia. Los afectos y lazos que se crean no son distintos si hay matrimonio o no". Llegando a una lectura amplia del artículo 226 CC, que permite conferir el cuidado personal a un tercero, a fin de permitir que sea este padre o madre afín quien continúe con la crianza del niño, cuando el padre o madre que tenía el cuidado hubiere fallecido, sobre cuando el contacto con el otro padre o madre era inexistente o casi nulo. MOMBERG AlARCón, Marcela (2010): "Familia Ensamblada y el Interés Superior del Niño", en: Revista de Derecho, Universidad de Concepción ( No 227-228, Año LXXVIII), pp. 132-133.

100 Para una visión comparada de la forma en que otros ordenamientos han afrontado esta problemática, consúltese Rivero, Francisco (2011): "De la Relación Fáctica a la Categoría Jurídica: La Figura del Padrastro y la Madrastra", en: Revista del Magister y Doctorado en Derecho, Escuela de Postgrado, Universidad de Chile ( $\left.{ }^{\circ} 4\right)$, pp. 165-188. 
efectivo reconocimiento se ve ciertamente complicado por la revalorización del ius sanguinis como elemento determinante en las relaciones paterno-filiales, debido al influjo del derecho a la identidad ${ }^{101}$. Finalmente, no ha de descartarse que la reticencia a regular esta materia diga relación con su posible conexión con otra problemática, la referida a la homoparentalidad.

\section{Matrimonio igualitario}

Desde su promulgación en 1855, el Código civil chileno contiene una definición de matrimonio en su artículo 102, que incorpora la diferencia de sexos entre sus contrayentes como de uno de los elementos que permite definir la institución, en términos tales que la doctrina ha entendido se trata de un elemento de la esencia de este contrato, cuya ausencia implicará la inexistencia del matrimonio ${ }^{102}$. Considerando la evolución de la problemática en el Derecho comparado, el tema sería retomado durante la discusión de la nueva ley de 2004, donde al menos en dos oportunidades nuestros legisladores discutieron sobre la admisibilidad de esta nueva figura por parte del ordenamiento jurídico chileno: cuando se trató de determinar su procedencia de cara a la nueva regulación matrimonial que se estaba creando, momento en que se descartó la aprobación de una regla especial, por considerarse que se trataba de una precisión innecesaria, habida consideración la definición vigente de matrimonio ${ }^{103}$; y al momento de determinar los efectos que el ordenamiento jurídico chileno reconocería a los matrimonios entre personas del mismo sexo celebrados válidamente conforme a la legislación de un país extranjero, instancia en que se acordaría la inclusión del actual artículo 80 de la Ley $N^{\circ} 19.947$, el cual exige la diferencia de sexos entre los contrayentes a fin que este matrimonio pueda desarrollar sus efectos en Chile ${ }^{104}$. A partir de esa fecha, se presentarían por congresistas de derecha sucesivos proyectos de

${ }^{101}$ Con todo, creemos posible realizar una lectura de nuestra legislación civil que comprenda el derecho a la identidad como uno de los elementos que integra una normativa cuya finalidad es la protección del interés superior del niño, donde tienen cabida los elementos dinámicos de esta misma y otros derechos de rango constitucional. Cornejo Aguilera, Pablo (2010): "Estatuto Filiativo y Derechos Constitucionales", en: Derecho y Humanidades (No 16, Vol. 2), pp. 43-61.

102 Por ejemplo, ver BarRientos Grandón, Javier (2011): Derecho de las Personas. El Derecho Matrimonial (Santiago, Editorial Abeledo-Perrot), pp. 285-287; BarRIEntos Grandón, Javier (2006): “De la Inexistencia del Matrimonio en el Derecho Chileno", en: Revista de Derecho, Universidad Austral, Valdivia (Vol. XIX, No 2), pp. 64-65.

103 Segundo Informe de la Comisión de Constitución, Legislación y Justicia del Senado, Historia de la Ley № 19.947, p. 1686.

104 Primer Informe de la Comisión de Constitución, Legislación y Justicia del Senado, Historia de la Ley No 19.947, p. 482. Consúltese también, Escanilla Meneses, Marta (2005): Matrimonio y Divorcio en Chile (Santiago, Ediciones Metropolitana), pp. 163-165. 
reforma constitucional ${ }^{105}$, destinados a incorporar en la carta fundamental la diferencia de sexos como uno de los elementos que definen al matrimonio, en el contexto de protección de la familia; y un único proyecto por parte de congresistas de izquierda ${ }^{106}$, destinado a cambiar la definición legal de matrimonio, a fin de eliminar la diferencia de sexos como uno de sus requisitos esenciales. Sin embargo, ninguna de las señaladas iniciativas legales sería siquiera objeto de discusión parlamentaria, manteniéndose la situación legislativa descrita de forma inalterada.

Por su parte, la judicialización del debate sobre el matrimonio igualitario se produciría en Chile como consecuencia de la interposición de una acción constitucional de protección patrocinada por abogados vinculados al Movimiento de Integración y Liberación Homosexual (MOVILH) ${ }^{107}$ en representación de cuatro parejas de personas del mismo sexo, a quienes se les impidió, o bien iniciar los trámites destinados a la celebración de su matrimonio conforme a la ley chilena, o bien inscribir ante el Servicio de Registro Civil e Identificación su unión matrimonial celebrada válidamente ante una jurisdicción extranjera, fundado en el carácter arbitrario que tendría la actuación de la funcionaria del servicio requerido, que lesionaba a juicio de los recurrentes el derecho a la igualdad ante la ley reconocido en el artículo $19 \mathrm{~N}^{\circ} 2 \mathrm{CPol}$. El Servicio requerido solicitó el rechazo de la acción intentada, argumentando que el actuar de la oficial civil se encontraba en perfecta concordancia con la normativa legal vigente, de forma que mal podría hacerse un juicio de reproche (arbitrariedad) a su actuación ${ }^{108}$. La Corte de Apelaciones de Santiago, conociendo de estas alegaciones, advirtió que la determinación de la arbitrariedad en el caso concreto suponía un pronunciamiento respecto de la constitucionalidad de las normas legales que justificaban el actuar del servicio público requerido: por esta razón, como medida para mejor resolver, solicitó al Tribunal Constitucional un pronunciamiento sobre la constitucionalidad

\footnotetext{
105 Boletines Nos. 3863-07, 7198-07, 7458-07 y 7656-07.

${ }^{106}$ Boletín No 7099-07.

107 Para una revisión precisa de los antecedentes, consúltese MuÑoz LEÓN, Fernando (2011): "Que Hable Ahora o Calle para Siempre: La Ética Comunicativa de Nuestra Deliberación sobre el Matrimonio Igualitario", en: Revista de Derecho. Universidad Austral, Valdivia (Vol. XXIV, № 1), pp. 9-30.

108 Por el contrario, confirmando la inexistencia de un margen de discrecionalidad por parte de las autoridades administrativas, debe advertirse que, en el evento de haber sido inscrito el matrimonio entre personas del mismo sexo celebrado en el extranjero o de haberse iniciado los trámites tendientes a la celebración del matrimonio en Chile entre personas del mismo sexo, el oficial civil que participare en esos actos estaría incurriendo en un delito funcionario contemplado en el artículo 388 del Código penal, que tipifica la celebración o la inscripción de matrimonios prohibidos por la ley.
} 
del artículo 102 del Código civil (el artículo 80 de la Ley No 19.947 no fue objeto del requerimiento) ${ }^{109}$.

En este marco se dictó por el Tribunal Constitucional la sentencia de 3 de noviembre de 2011, cuyo voto de mayoría resuelve rechazar el requerimiento por una razón que, a primera vista, parece eminentemente formal, como es su carácter inidóneo para reformular el contenido de toda una institución ${ }^{110}$. Sin embargo, más allá de esta primera impresión, creemos que el correcto entendimiento de esta decisión supone considerar un elemento sustantivo fundamental, como es la comprensión del rol que le corresponde a esta magistratura en un sistema democrático. ¿Qué otra razón llevaría al Tribunal a resolver el rechazo del requerimiento por este motivo, después de haber declarado su admisibilidad formal por medio de otra resolución? ¿Qué otra razón explicaría que los miembros del Tribunal que concurrieron al voto de mayoría, rechazando el requerimiento por razones formales, hayan redactado extensas prevenciones, dando cuenta de sus concepciones sobre las exigencias que plantea el principio de igualdad, sobre la protección constitucional de la familia y sobre la posición institucional del matrimonio en el sistema chileno?

Por estas razones, consideramos que la clave para entender el razonamiento del voto de mayoría del Tribunal se encuentra en el considerando séptimo de la sentencia, donde los Ministros, después de haber reconocido que la regulación del matrimonio es un asunto entregado por la Constitución al legislador (considerandos quinto y sexto), descartan la existencia de una exigencia constitucional en orden a dotar a esta institución de un determinado contenido: la regulación del matrimonio queda entregada institucionalmente a aquel órgano que cuenta con una mayor legitimación política para adoptar esta decisión, como es el

\footnotetext{
109 Por su parte, el artículo 80 de la Ley № 19.947 no fue objeto del requerimiento, elemento de máxima importancia, dado que por esta razón el Tribunal Constitucional no pudo pronunciarse sobre su constitucionalidad. La sentencia que comentamos se refiere única y exclusivamente a la constitucionalidad de la definición de matrimonio contenida en el artículo 102 del Código civil. Sobre este punto, puede revisarse el considerando cuarto del voto de mayoría. Tribunal Constitucional, Sentencia Rol 1881-2010, de 3 de noviembre de 2011.

110 Así, según se consigna en el considerando noveno "[...] el requerimiento a que se refiere esta sentencia no puede prosperar, toda vez que lo que se pretende por su intermedio es que se reformule un sistema de normas de modo integral y se regule positivamente una institución de modo distintos al actual. En efecto, si bien se ha efectuado una impugnación aislada de un artículo, lo que verdaderamente se impugna es la aplicación de un estatuto jurídico complejo derivado del vínculo matrimonial entre hombre y mujer, que se encuentra regulado en su estructura esencial en el Código Civil y en la Ley No 19.947, esto es, la Ley de Matrimonio Civil. En otras palabras, lo que pretenden los recurrentes es que se les reconozca la aplicación del mencionado estatuto, cuestión que no es de competencia de este Tribunal, pues éste no se encuentra facultado para modificar y regular las instituciones que contempla el ordenamiento jurídico mediante un pronunciamiento de inaplicabilidad.[...]". Tribunal Constitucional, Sentencia Rol 1881-2010, de 3 de noviembre de 2011.
} 
legislador. Así, se señala en el considerando séptimo: "Que, a mayor abundamiento, cabe precisar que los efectos y la regulación de las proyecciones del matrimonio son propios de la reserva legal y no constitucional. Ello quedó en evidencia en la discusión de la Comisión de Estudio de la Nueva Constitución, referida a la disolución del matrimonio la que, además, con posterioridad a la entrada en vigencia de la Carta de 1980, fue aceptada y regulada bajo la forma del divorcio vincular. Es así como las características de la discusión, referidas a la protección y desarrollo de la misma, han podido mutar en virtud de diversas normas de rango legal, las que han efectuado cambios en lo que atañe, por ejemplo, al régimen de bienes, a la adopción y a la filiación, entre otros aspectos; ${ }^{111} 11$

Como se puede apreciar, la decisión adoptada por el Tribunal Constitucional chileno sigue lo resuelto por la Corte Europea de Derechos Humanos en Schalk y Köpf v. Austria ${ }^{112}$ y lo recientemente dictaminado por el Consejo Constitucional francés en su Decisión 2010-92 ${ }^{113}$ (sentencias que son citadas en sus prevenciones por todos los Ministros, salvo Bertelsen), presentando en el contexto de la discusión sobre el matrimonio igualitario en Chile una importancia fundamental: la razón por la cual se rechazó el requerimiento fue por considerarse que corresponde al legislador definir si las parejas del mismo sexo deben o no tener acceso al matrimonio y no por considerarse que existe una exigencia constitucional en orden a que el matrimonio se construya considerando esta diferencia. De esta forma, el Tribunal alteró el marco dentro del cual se estaba desarrollando el debate, al negar uno de los puntos más férreamente sostenido por los detractores del matrimonio igualitario, como es el que se trate de una institución cuyo marco se encuentre previamente determinado por el constituyente.

Por esta razón, el principal efecto que sigue de la sentencia en comento es (en principio) circunscribir la discusión sobre el matrimonio igualitario al ámbito legal, reconociendo en el legislativo al poder competente para definir las condiciones para acceder a la institución matrimonial, para establecer los requisitos que deben ser satisfechos en su celebración, y para regular los efectos y proyecciones que en el ordenamiento su celebración acarreará; en una solución que se encuentra acorde con la primacía que debe ser atribuida

\footnotetext{
111 Tribunal Constitucional, Sentencia Rol 1881-2010, de 3 de noviembre de 2011.

112 Corte Europea de Derechos Humanos, 24 de junio de 2010, "Schalk and Kopf v. Austria", Aplicación No. 30141/04. Disponible en: http://cmiskp.echr.coe.int/tkp197/view.asp?action=html\&docume ntld=870476\&portal=hbkm\&source $=$ externalbydocnumber\&table=F69A27FD8FB86142BF01C1166 DEA398649 [visitado el 29/04/2013].

${ }^{113}$ Consejo Constitucional de Francia, Sentencia No 2010-92 QPC de 28 de enero de 2011. Disponible en: http://www.conseil-constitutionnel.fr/conseil-constitutionnel/root/bank/pdf/conseil-constitutionnel-98620.pdf [visitado el 29/04/2013].
} 
a la legislatura, por su carácter representativo, en un sistema democrático. En definitiva, la sentencia constituye una invitación a definir la manera en que será entendida esta institución de primera importancia social mediante un proceso deliberativo sujeto a las reglas de las decisiones democráticas ${ }^{114-115}$.

\section{Conclusiones}

Según se ha expuesto en el presente artículo, la regulación del Derecho de familia en Chile es una de las materias que más profundas transformaciones ha experimentado desde la promulgación del Código civil en 1855, evolución que avanza cada vez más hacia el reconocimiento de un verdadero Derecho de las familias, de carácter pluralista, encargado antes de proveer protección a las diversas formas en que esta realidad se puede expresar en la vida social, que a trazar normativamente un modelo ideal de familia. Sin embargo, se trata todavía

\footnotetext{
114 En este mismo sentido, criticando interpretaciones que buscan "constitucionalizar" la definición de la institución matrimonial, como las sostenidas por el profesor CORRAL, el profesor CONTRERAS señala que el efecto que estas posiciones tienen es el de "expropiar el asunto de la decisión democrática mayoritaria. En otras palabras [continúa el autor citado], se busca evitar que la definición del derecho y de la institución del matrimonio sea resuelto políticamente. Su 'constitucionalización' la convierte en una cuestión contramayoritaria. En definitiva, CORRAL teme al resultado de la decisión política democrática". Contreras Vásquez, Pablo (2012): "Reserva Legal y Matrimonio Homosexual", en: Diario Constitucional. Disponible en: http://diarioconstitucional.cl/mostrararticulo.php?id=114\&idautor=100 [visitado el 29/04/2013].
}

115 Sin embargo, Ilamativamente, el primer órgano que tomó la palabra en este debate fue uno que no goza de legitimidad democrática propia y que, incluso, ha recibido durante el año 2012 un fuerte cuestionamiento internacional por la forma como una de sus decisiones afectó el principio de igualdad en desmedro de los derechos de una madre lesbiana [Nos referimos al caso de Karen Atala. v. Corte Interamericana de Derechos Humanos, Caso Atala Riffo y niñas vs. Chile, sentencia de 24 de febrero de 2012.] Se trata de la Corte Suprema. En la sentencia de segunda instancia dictada en el proceso de protección, la Corte, después de exponer correctamente que el rechazo del requerimiento de inaplicabilidad en definitiva impedía acoger el recurso, pues resulta imposible calificar de ilegal o de arbitrario el actuar de un funcionario en cumplimiento de una norma legal que pasó el test del Tribunal Constitucional, toma un decidido partido en la discusión, haciendo suyas las prevenciones contenidas en el voto de uno de los Ministros. Así, declara en su considerando sexto "Que en todo caso y con la finalidad de hacerse cargo de la alegación expuesta en el recurso de apelación acerca de la infracción a la igualdad ante la ley, cabe hacer presente que este tribunal coincide con lo expresado por el Ministro del Tribunal Constitucional don Raúl Bertelsen Repetto en su voto de prevención en los autos rol 1881-10, especialmente cuando razona: 'Que, teniendo en cuenta que es materia de ley la regulación del matrimonio, la definición del mismo contenida en el artículo 102 del Código Civil de 1855 y mantenida en la nueva Ley de Matrimonio Civil de 2004, al reservar su celebración sólo a personas de distinto sexo, no puede estimarse que constituye una diferencia arbitraria o caprichosa, sino fundamentada en las diferencias entre varón y mujer, que la ley, legítimamente ha considerado y puede seguir considerando relevantes para establecer que los contrayentes sólo pueden ser un hombre y una mujer, razón por la que se conforma con la garantía constitucional de la igualdad ante la ley y de ahí que la aplicación judicial del precepto no resulta contraria a la Constitución". Corte Suprema, Sentencia Rol 12.635-2011, de 4 de abril de 2012. 
de un proceso inconcluso, resultado del nacimiento de nuevas demandas de regulación o simplemente debido al cambio de percepciones que se produce como consecuencia de la evolución social, o del cada vez mayor influjo de los derechos fundamentales en el ámbito del Derecho privado. Por esta razón, no es de extrañar que en la actualidad se estén discutiendo importantes reformas, que tocan tanto el ámbito de las relaciones de pareja (acuerdo de vida, sociedad conyugal) como las relaciones paterno-filiales (cuidado compartido), las cuales aparecen inspiradas por el pleno reconocimiento del principio de igualdad y por la visión pluralista de familia antes señalada. Finalmente, se expuso acerca de dos temas cuyo desarrollo futuro, si bien es esperable (la protección de la familia ensamblada y el matrimonio igualitario), no puede considerarse a corto plazo, por la existencia de fuertes resistencias a nivel político y social.

Como reflexión final, nos interesa destacar la necesaria coherencia que deben tener todas estas reformas, tanto con los fines por ellas perseguidas, como con los principios que inspiran esta particular rama del Derecho, a fin de poder concebir los cambios que se van produciendo como un proceso de transformación evolutiva que gira siempre en torno a una realidad social reconocible por las insustituibles funciones de apoyo material y afectivo que está Ilamada a desempeñar en la vida de cada persona. 